ornl

OAK RIDGE

NATIONAL

LABORATORY

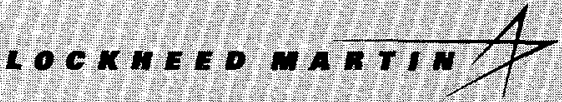

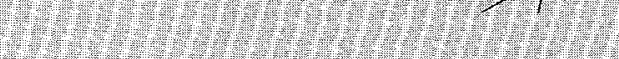

13

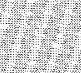

$\sqrt{1.1}$

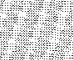

1)(.).

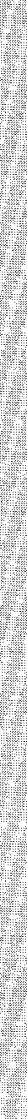

UANAGED AND OPERATED BY

LOCKHEED MARTN ENERGY RESEARCH CORPORATION

FOR THE UNTED STATES

DEPARTIUENT OF ENERGY

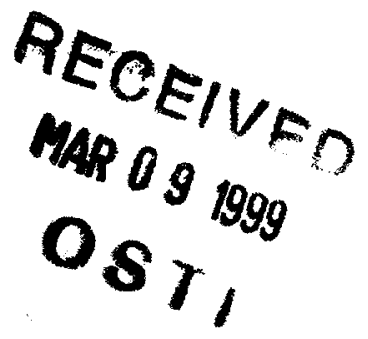

ORNL/M-6629

Quarterly Progress Report for the Chemical and Energy Research Section of the Chemical Technology Division: October-December 1997

R. T. Jubin 
This report has been reproduced from the best available copy.

Reports are available to the public from the following source.

National Technical Information Service

5285 Port Royal Road

Springfield, VA 22161

Telephone 703-605-6000 (1-800-553-6847)

TDD 703-487-4639

Fax 703-605-6900

E-mail orders@ ntis.fedworld.gov

Web site http://www.ntis.gov/ordering.htm

Reports are available to U.S. Department of Energy (DOE) employees, DOE contractors, Energy Technology Data Exchange (ETDE) representatives, and International Nuclear Information System (INIS) representatives from the following source.

Office of Scientific and Technical information

P.O. Box 62

Oak Ridge, TN 37831

Telephone 423-576-8401

Fax 423-576-5728

E-mail reports@adonis.osti.gov

Web site http://www.osti.gov/products/sources.html

Reports produced after January 1, 1996, are generally available via the DOE Information Bridge.

Web site http://www.doe.gov/bridge 


\section{DISCLAIMER}

This report was prepared as an account of work sponsored by an agency of the United States Government. Neither the United States Government nor any agency thereof, nor any of their employees, makes any warranty, express or implied, or assumes any legal liability or responsibility for the accuracy, completeness, or usefulness of any information, apparatus, product, or process disclosed, or represents that its use would not infringe privately owned rights. Reference herein to any specific commercial product, process, or service by trade name, trademark, manufacturer, or otherwise does not necessarily constitute or imply its endorsement, recommendation, or favoring by the United States Government or any agency thereof. The views and opinions of authors expressed herein do not necessarily state or reflect those of the United States Government or any agency thereof. 


\section{DISCLAIMER}

Portions of this document may be illegible in electronic image products. Images are produced from the best available original document. 


\author{
Chemical Technology Division
}

\title{
QUARTERLY PROGRESS REPORT FOR THE CHEMICAL AND ENERGY RESEARCH SECTION OF THE CHEMICAL TECHNOLOGY DIVISION: OCTOBER-DECEMBER 1997
}

R. T. Jubin

Date Published-February 1999

\author{
Prepared by the \\ OAK RIDGE NATIONAL LABORATORY \\ Oak Ridge, Tennessee 37831-6285 \\ managed by \\ LOCKHEED MARTIN ENERGY RESEARCH CORP. \\ for the \\ U.S. DEPARTMENT OF ENERGY \\ under contract DE-AC05-96OR22464
}





\section{CONTENTS}

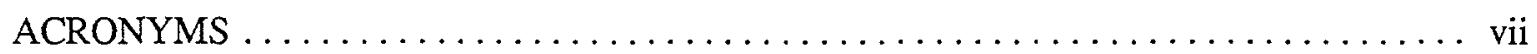

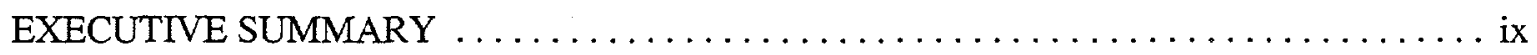

1. HOT CELL OPERATIONS $\ldots \ldots \ldots \ldots \ldots \ldots \ldots \ldots \ldots \ldots \ldots \ldots \ldots \ldots$

1.1 SLUDGE-PARTITIONING CHEMISTRY $\ldots \ldots \ldots \ldots \ldots \ldots \ldots \ldots \ldots \ldots$

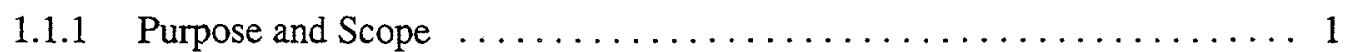

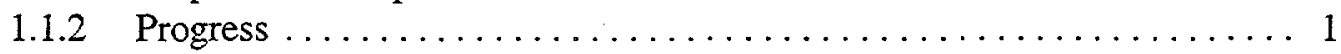

1.2 HOT DEMONSTRATION OF PROPOSED COMMERCIAL NUCLIDE

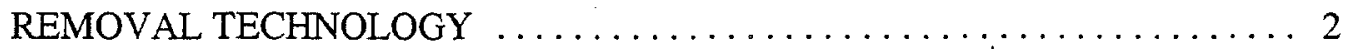

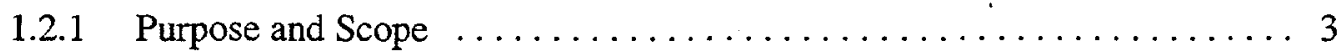

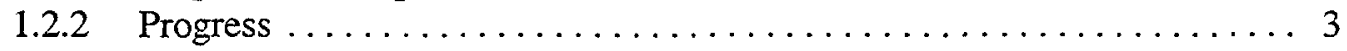

1.2.2.1 Continuation of the AEAT EIX Technology Testing ........ 3

1.2.2.2 Cell Resin Loadings $\ldots \ldots \ldots \ldots \ldots \ldots \ldots \ldots \ldots \ldots \ldots$

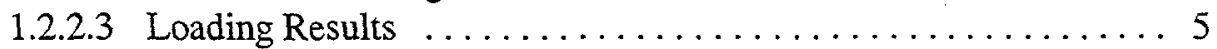

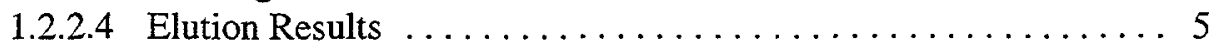

1.2.2.5 Analysis of the Resin and Cells After the Loadings . . . . . . . 6

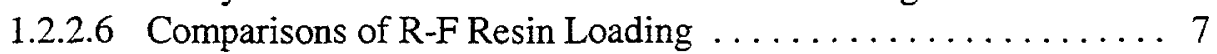

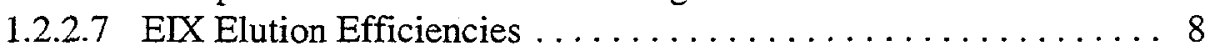

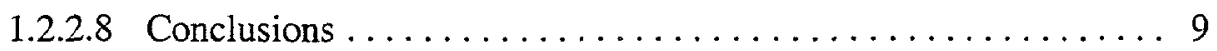

1.3 DEVELOPMENT AND TESTING OF INORGANIC SORBENTS $\ldots \ldots \ldots \ldots 10$

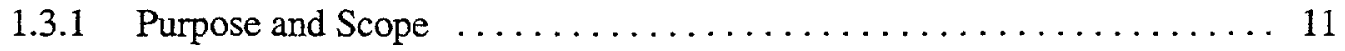

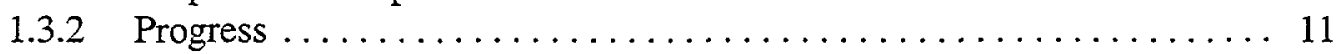

2. PROCESS CHEMISTRY AND THERMODYNAMICS $\ldots \ldots \ldots \ldots \ldots \ldots \ldots \ldots$

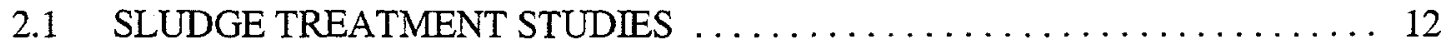

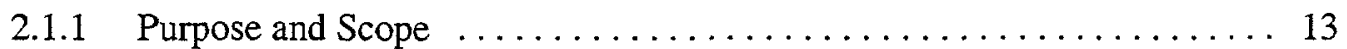

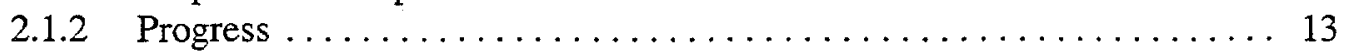

2.2 THERMODYNAMICS AND KINETICS OF ENERGY-RELATED

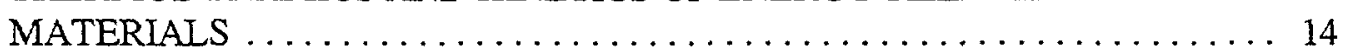

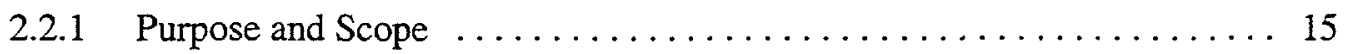

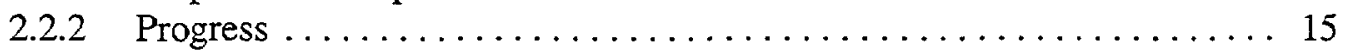

2.2.2.1 Solidification of the Y-Ba-Cu-O System $\ldots \ldots \ldots \ldots \ldots \ldots 15$

2.2.2.2 Oxidation States of Copper and Oxygen in $1: 2: 3: n \ldots \ldots \ldots 15$

2.2.2.3 Collaborations ...................... 16

3. SEPARATIONS AND MATERIALS SYNTHESIS $\ldots \ldots \ldots \ldots \ldots \ldots \ldots \ldots \ldots \ldots$

3.1 CHEMICAL AND PHYSICAL PRINCIPLES IN MULTIPHASE

SEPARATIONS . . . . . . . . . . . . . . . . . . . . 17

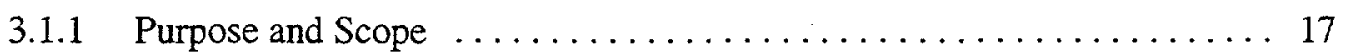

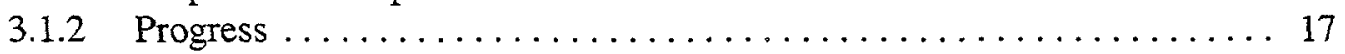

3.1.2.1 Drop Deformation and Breakup ............... 17

3.1.2.2 Wetting and Stability of Drops on Solid Surfaces ......... 18

3.1.2.3 Spraying and Mixing in Electrohydrodynamic Flows ....... 18 
3.2 NUCLEATION, GROWTH, AND TRANSPORT PHENOMENA $\ldots \ldots \ldots \ldots 18$

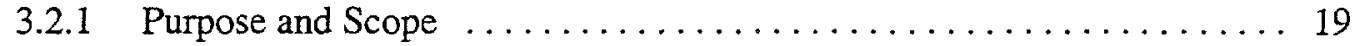

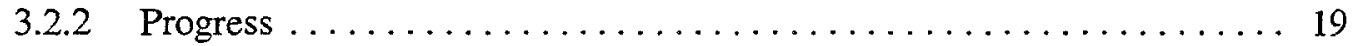

3.3 PHASE EQUILIBRIA MODIFICATION BY ELECTRIC FIELDS . . . . . . . . 20

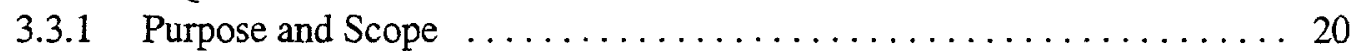

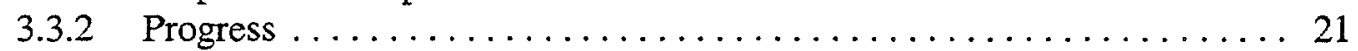

3.4 MAGNETIC-SEEDING FILTRATION $\ldots \ldots \ldots \ldots \ldots \ldots \ldots \ldots \ldots \ldots \ldots \ldots \ldots \ldots$

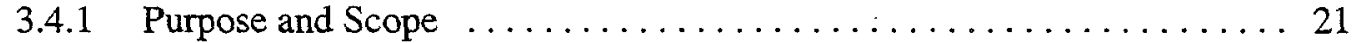

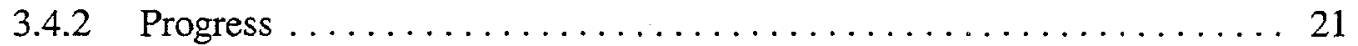

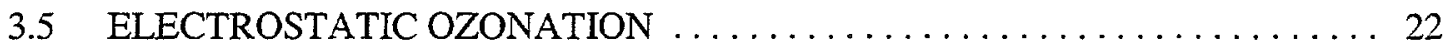

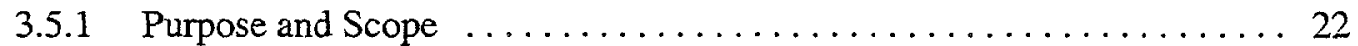

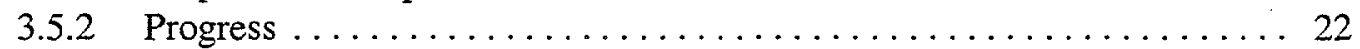

3.6 DEVELOPMENT PROGRAM IN ELECTRODISTILLATION $\ldots \ldots \ldots \ldots \ldots 23$

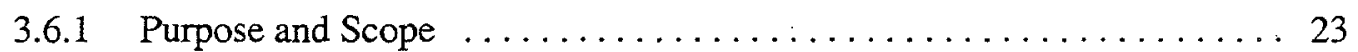

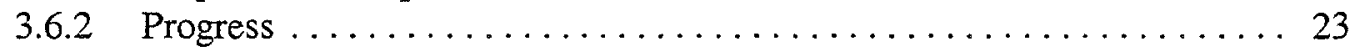

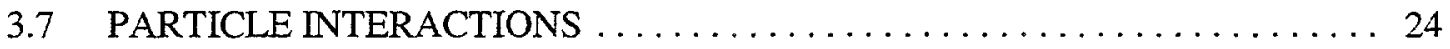

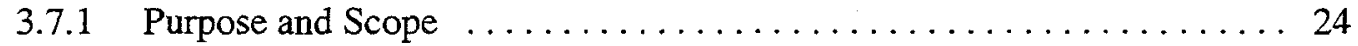

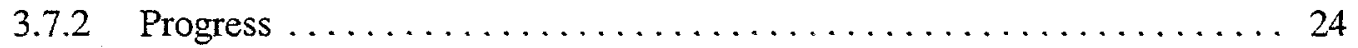

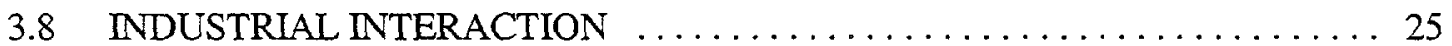

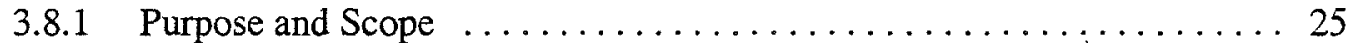

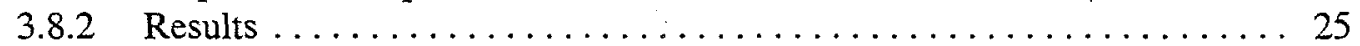

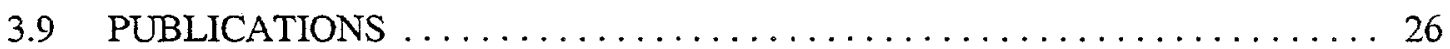

4. FLUTD STRUCTURE AND PROPERTIES $\ldots \ldots \ldots \ldots \ldots \ldots \ldots \ldots \ldots \ldots \ldots \ldots$

4.1 INTERACTIONS OF SOLUTES, SOLVENTS, AND SURFACES $\ldots \ldots \ldots \ldots 27$

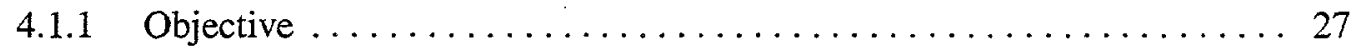

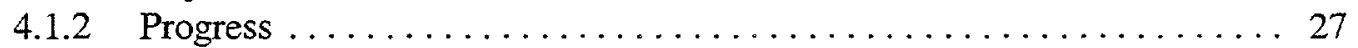

4.2 MOLECULAR-BASED STUDY OF REVERSE MICELLES IN

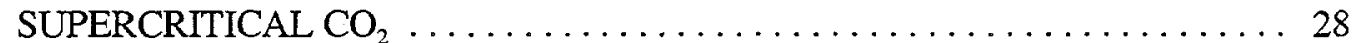

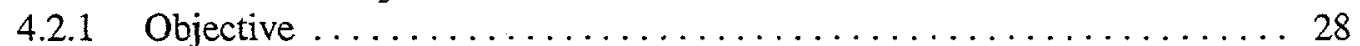

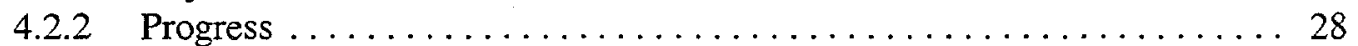

4.3 STRUCTURE AND PROPERTIES OF CHAIN MOLECULE

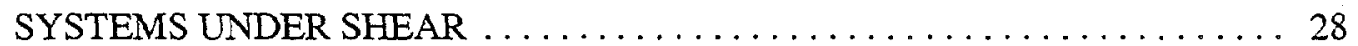

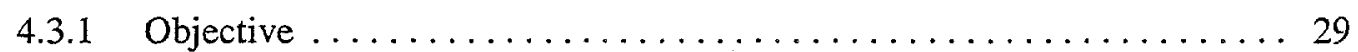

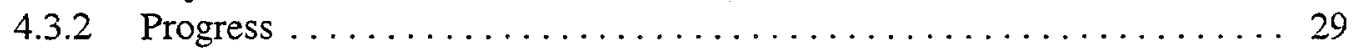

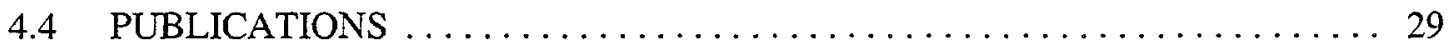

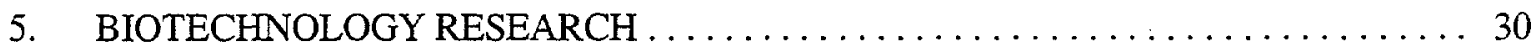

5.1 KINETICS OF ENZYME-CATALYZED REACTIONS $\ldots \ldots \ldots \ldots \ldots \ldots . \ldots$ 


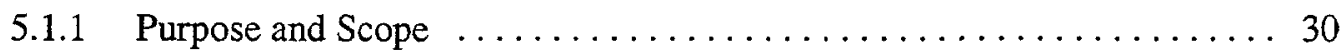

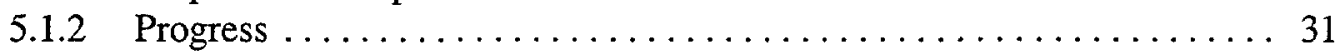

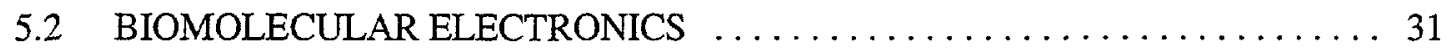

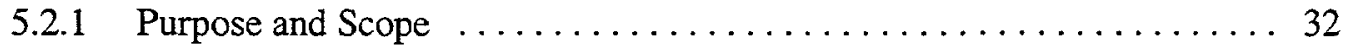

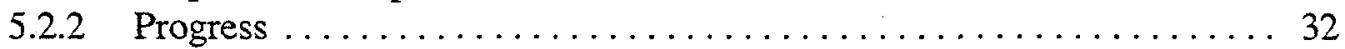

5.3 RENEWABLE HYDROGEN PRODUCTION $\ldots \ldots \ldots \ldots \ldots \ldots \ldots \ldots \ldots \ldots \ldots \ldots \ldots \ldots$

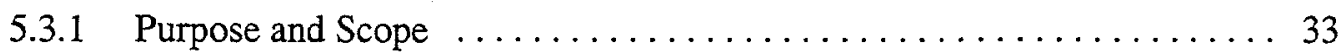

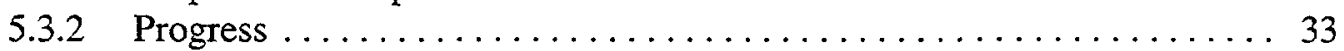

5.4 ENZYMES FROM EXTREMOPHILES IN BIOPROCESSING AND

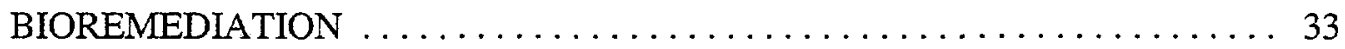

5.5 ENZYMATIC CONVERSION OF BIOMASS TO HYDROGEN . . . . . . 35

5.6 DEVELOPMENT OF MICROCYCLE TECHNOLOGY FOR THE

LARGE-SCALE PRODUCTION OF FUNGAL ENZYMES . . . . . . . . . . 35

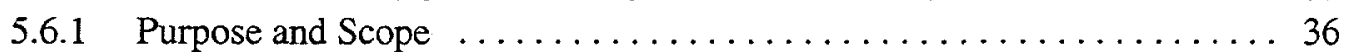

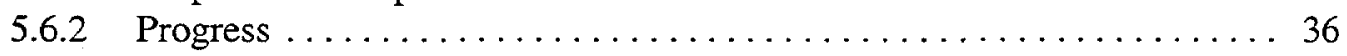

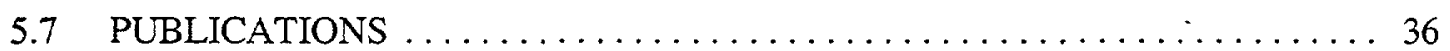

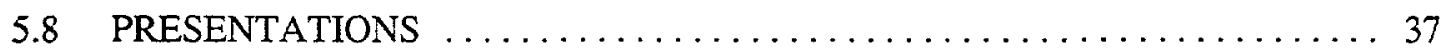

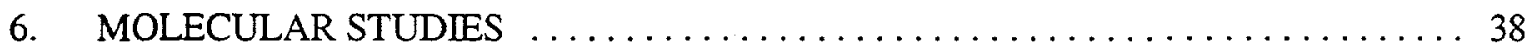

6.1 AQUEOUS ELECTROLYTE SOLUTIONS AT AMBIENT AND

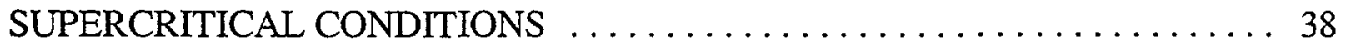

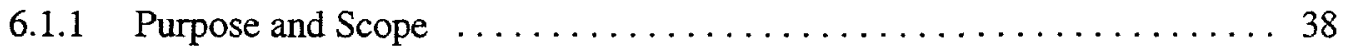

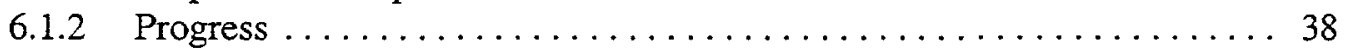

6.2 THEORY AND MOLECULAR SIMULATION OF NONEQUILIBRIUM SYSTEMS . . . . . . . . . . . . . . . . . . . . . 39

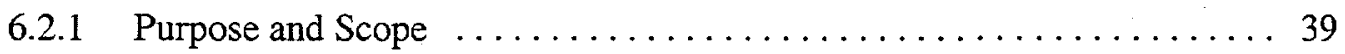

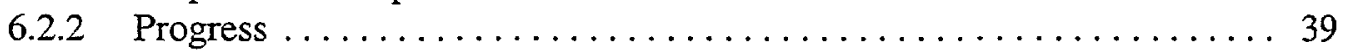

6.3 INTEGRAL EQUATION THEORIES OF MOLECULAR FLUIDS $\ldots \ldots \ldots .39$

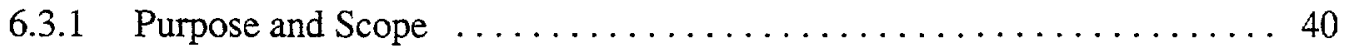

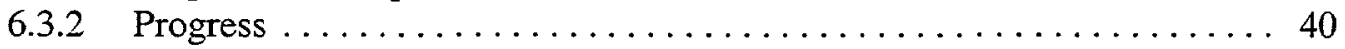

6.4 MATHEMATICAL MODELING OF BACTERIAL MIGRATION THROUGH POROUS MEDIA WITH APPLICATION TO IN SITU BIOREMEDIATION . . 40

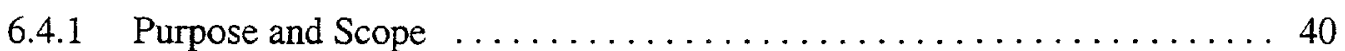

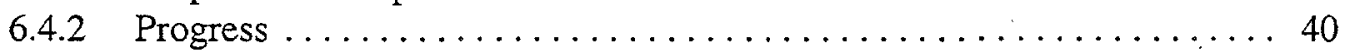

6.5 FUNDAMENTAL CHEMISTRY AND THERMODYNAMICS OF

HYDROTHERMAL OXIDATION PROCESSES $\ldots \ldots \ldots \ldots \ldots \ldots \ldots \ldots$

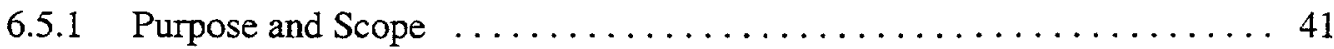

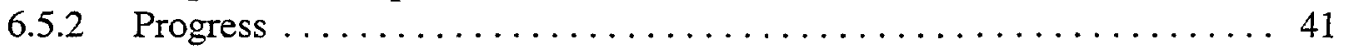


6.6 DEVELOPMENT AND APPLICATION OF FAST COMPUTATIONAL PROTEIN-FOLDING ALGORITHMS USING MASSIVELY PARALLEL

SUPERCOMPUTERS $\ldots \ldots \ldots \ldots \ldots \ldots \ldots \ldots \ldots \ldots \ldots \ldots \ldots \ldots \ldots$

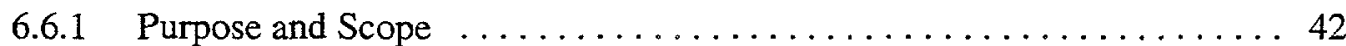

6.6 .2 Progress .............................. 42

6.7 MOLECULAR-BASED STUDY OF REVERSED MICELLES IN

SUPERCRITICAL CARBON DIOXIDE FOR SOLVENT

SUBSTITUTION IN THE U.S. CHEMICAL INDUSTRY . . . . . . . . . . 42

6.8 OTHER IMPORTANT ACTIVITIES $\ldots \ldots \ldots \ldots \ldots \ldots \ldots \ldots \ldots \ldots \ldots \ldots \ldots \ldots \ldots$

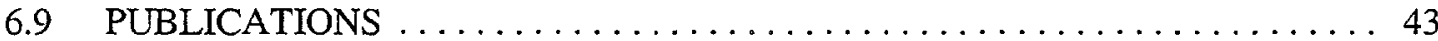

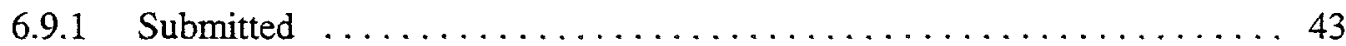

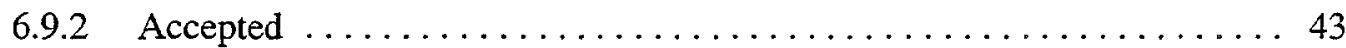

6.9 .3 Published $\ldots \ldots \ldots \ldots \ldots \ldots \ldots \ldots \ldots \ldots \ldots \ldots \ldots \ldots \ldots \ldots \ldots$

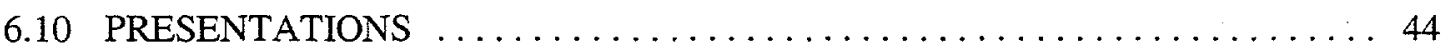

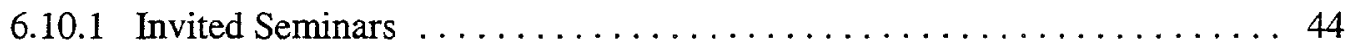

6.10 .2 Invited Conferences . . . . . . . . . . . . . . . . . . . 44

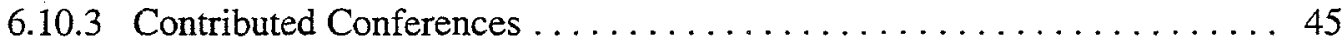




\section{ACRONYMS}

$\begin{array}{ll}\text { AEAT } & \text { AEA Technology } \\ \text { AMP } & \text { ammonium molybdophosphate } \\ \text { BES } & \text { Basic Energy Sciences (DOE) } \\ \text { CMC } & \text { carboxymethylcellulose } \\ \text { CSRD } & \text { Cesium Removal Demonstration } \\ \text { CST } & \text { crystalline silicotitanate } \\ \text { CV } & \text { column volumes } \\ \text { DI } & \text { deionized } \\ \text { DOE } & \text { U.S. Department of Energy } \\ \text { DTA } & \text { differential thermal analysis } \\ \text { EHD } & \text { electrohydrodynamic } \\ \text { EIX } & \text { electrochemical ion exchange } \\ \text { ESP } & \text { Efficient Separations and Processing Crosscutting Program (DOE) } \\ \text { ESW } & \text { Enhanced Sludge Washing } \\ \text { HLW } & \text { high-level waste } \\ \text { HTML } & \text { High Temperature Materials Laboratory (ORNL) } \\ \text { INEEL } & \text { Idaho National Engineering and Environmental Laboratory } \\ \text { MVST } & \text { Melton Valley Storage Tank } \\ \text { NEMD } & \text { nonequilibrium molecular dynamics } \\ \text { ORNL } & \text { Oak Ridge National Laboratory } \\ \text { PAN } & \text { polyacrylonitrile } \\ \text { PSI } & \text { Photosystem I } \\ \text { PSII } & \text { Photosystem II } \\ \text { RCRA } & \text { Resource Conservation and Recovery Act } \\ \text { R-F } & \text { resorcinol-formaldehyde } \\ \text { SANS } & \text { small-angle neutron scattering } \\ \text { SAXS } & \text { small-angle X-ray scattering } \\ \text { TFA } & \text { Tank Focus Area } \\ \text { TGA } & \text { thermogravimetric analysis } \\ \text { VLE } & \text { vapor-liquid equilibrium (equilibria) } \\ \text { XRD } & \text { X-ray diffraction } \\ \text { ZrHP } & \text { zirconium monohydrogen phosphate(s) } \\ & \end{array}$




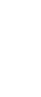

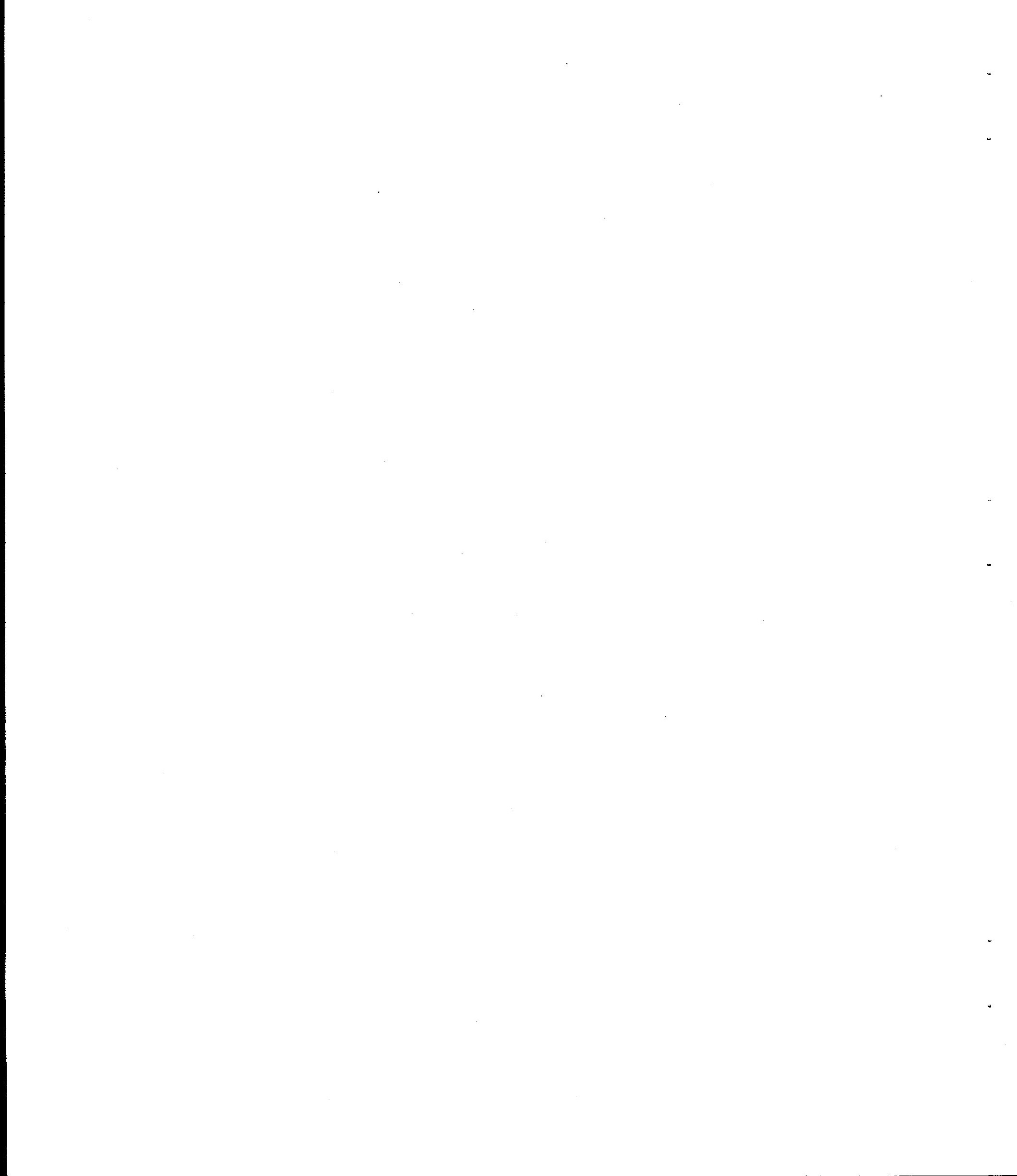
. 


\section{EXECUTIVE SUMMARY}

This report summarizes the major activities conducted in the Chemical and Energy Research Section of the Chemical Technology Division at Oak Ridge National Laboratory (ORNL) during the period October-December 1997. The section conducts basic and applied research and development in chemical engineering, applied chemistry, and bioprocessing, with an emphasis on energy-driven technologies and advanced chemical separations for nuclear and waste applications.

The report describes the various tasks performed within six major areas of research: Hot Cell Operations, Process Chemistry and Thermodynamics, Separations and Materials Synthesis, Fluid Structure and Properties, Biotechnology Research, and Molecular Studies. The name of a technical contact is included with each task described, and readers are encouraged to contact these individuals if they need additional information.

Activities conducted within the area of Hot Cell Operations included efforts to optimize the processing conditions for Enhanced Sludge Washing of Hanford tank sludge, the testing of candidate absorbers and ion exchangers under continuous-flow conditions using actual supernatant from the Melton Valley Storage Tanks, and attempts to develop a cesium-specific spherical inorganic sorbent for the treatment of acidic high-salt waste solutions.

Within the area of Process Chemistry and Thermodynamics, the problem of solids formation in process solutions from caustic treatment of Hanford sludge was addressed and experimental collaborative efforts with Russian scientists to determine the solidification conditions of yttrium, barium, and copper oxides from their melts were completed.

In the area of Separations and Materials Synthesis, fundamental studies explored the use of electromagnetic fields to enhance transport processes in multiphase separations; investigated nucleation and particle growth in systems for the synthesis, characterization, application, and processing of ultrafine particles; and examined the use of electric fields to modify phase equilibria in multiphase separations processes. Other efforts involved the application of magnetic-seeding filtration to remove solids from waste streams and the enhancement of oxidation of organic pollutants in aqueous solutions by using electric fields to form microbubbles containing ozone. Additional initiatives within this area involved the use of electric fields to improve distillation efficiency and the investigation of particle interactions in reactive systems. Areas of possible industrial interaction were also investigated.

Fluid Structure and Properties included molecular-based studies of solutions in supercritical fluids, a multi-institutional initiative to develop a molecular understanding of reverse miscelles in supercritical carbon dioxide through experimentation and molecular simulation calculations, and molecular-based prediction of the structure and properties of long-chain molecules undergoing shear flow.

Within the area of Biotechnology Research, four new Hill reagents-each capable of photosynthetic reduction to form a metallic catalyst in the thylakoid membrane-were identified. In related research, Kelvin probe force microscopy was used to measure charge separation in a single photosystem I reaction center, while infrared spectroscopy was used to measure the absolute yields of carbon dioxide uptake per mole of chlorophyll per flash of light. In enzyme-related work, the kinetic characteristics of thermophilic microorganisms were studied, efforts were made to maximize 
the efficiency of the enzymatic production of hydrogen from glucose, and preparations were made to cultivate test fungi under a microcycle regime.

In the final area-Molecular Studies-as part of an effort to enhance our microscopic-level understanding of aqueous electrolyte solutions, development of a simulation code for water with a flexible potential was initiated. Related tasks included the investigation of simulation algorithms for nonequilibrium systems and the development of a statistical mechanical approach to model the structural properties of liquid metals. Also in progress were refinement of an efficient code for modeling in situ bioremediation processes and extension of a molecular formalism to reaction kinetics in supercritical fluid solvents. A new project was initiated involving parallel implementations of the Geocore algorithm, with the goal of developing more rapid, less exhaustive algorithms for very large proteins. 


\title{
1. HOT CELL OPERATIONS
}

\author{
E. C. Beahm
}

\subsection{SLUDGE-PARTITIONING CHEMISTRY (R.D. Hunt, J.L. Collins, and C. W. Chase)}

Contact: R. D. Hunt

Telephone: (423) 574-5481

Internet: huntrd@ornl.gov
Contact: J. L. Collins

Telephone: (423) 574-6689

Internet: collinsjl@ornl.gov

Summary: The problem safety summary for these parametric studies on sludge samples from Hanford tanks S-101 and C-103 has been approved. The experimental apparatus for the S-101 and C-103 sludge experiments has been successfully tested with sludge simulants. A 111-g sample of sludge from Hanford tank S-101 was washed four times (16-143 h) with inhibited water at ambient temperature. Approximately $32 \%$ of the initial sludge sample was removed during the four washes. A fifth water wash was performed at $98^{\circ} \mathrm{C}$ in an effort to remove more solids.

\subsubsection{Purpose and Scope}

Many underground storage tanks at Hanford contain high concentrations of nonradioactive materials such as aluminum and sodium that can significantly increase the volume of the final highlevel waste (HLW) for disposal. Other less abundant inert components, such as chromium and phosphate, can also increase the volume of the HLW product from vitrification processes. The U.S. Department of Energy (DOE) can reduce the costs of long-term storage and disposal of HLW if these nonradioactive components are removed from the HLW before it is immobilized. DOE has selected Enhanced Sludge Washing (ESW) as its baseline technology to separate key inert components from the radionuclides in the HLW sludges. ESW refers to simple sludge washing, followed by caustic leaching with $2-3 \mathrm{M} \mathrm{NaOH}$ at an elevated temperature. The leached solids are then washed with the dilute $\mathrm{NaOH}$ to remove the dissolved components and the added $\mathrm{NaOH}$. This process is effective because of the increased solubility of some of these inert components under very caustic conditions, which can be used to partition the radioactive and nonradioactive components.

The primary objective of this task is to optimize the processing conditions for the ESW of sludges from Hanford tanks S-101 and C-103. The effects of process variables such as $\mathrm{NaOH}$ concentration, temperature, and leaching time on the efficacy of the caustic leaching process will be determined under more realistic processing conditions.

\subsubsection{Progress}

This task continues to study the potential of caustic solutions ESW to remove aluminum and other nonradioactive components from Hanford tank sludges so the volume of the high-level-waste 
stream can be reduced. Parametric studies on sludge samples from Hanford tanks S-101 and C-103 will determine the effects of two different temperatures $\left(70\right.$ and $\left.95^{\circ} \mathrm{C}\right)$, two different $\mathrm{NaOH}$ concentrations ( 1 and $3 \mathrm{M}$ ), and four different leaching times $(5,24,72$, and $168 \mathrm{~h}$ ) on the performance of the ESW procedure.

The problem safety summary for these parametric studies has been approved. Work on the experimental apparatus for the S-101 and C-103 sludge experiments has been completed. Sludge simulants were used to test the performance of the system. A key component in the system is the mixer for washed sludge slurry. Tests indicate that the mixer can generate the required number of uniform sludge samples to be leached with caustic. The uniform samples will permit direct comparisons between all of the test results.

A 111 -g sample of sludge from Hanford tank S-101 was washed four times (16-143 h) with inhibited water at ambient temperature. The volume of inhibited water in the combined washes was approximately $409 \mathrm{~mL}$. After each wash, the sample was centrifuged, the water was decanted, and the remaining wet solids were weighed. Based on the final sample weight, approximately $32 \%$ of the initial sludge sample was removed during the four washes. A fifth water wash was performed at $98^{\circ} \mathrm{C}$ in an effort to remove additional solids. An earlier study had effectively washed a small sludge sample from Hanford tank S-101 at $100^{\circ} \mathrm{C}$.

\subsection{HOT DEMONSTRATIONOF PROPOSED COMMERCIAL NUCLIDE REMOVAL TECHNOLOGY (D. D. Lee and J. R. Travis)}

Contact: D. D. Lee

Telephone: (423) 576-2689

Internet: leedd@ornl.gov

Summary: This task covers work in the continuous removal and concentration of radioactive components of supernatant at the various DOE sites. The primary objective is to test candidate absorbers and ion exchangers under continuous-flow conditions using actual supernatant from the Melton Valley Storage Tanks (MVSTs). An experimental system contained in a hot cell facility is used to test the materials in columns or modules using the same batch of supernatant so that they can all be compared on the same basis. The system was also used in support of the Cesium Removal Demonstration (CsRD) program to qualify crystalline silicotitanate (CST) sorbent and MVST supernatant processed by the CsRD. It would also determine if the CST removes other radionuclides or Resource Conservation and Recovery Act (RCRA) metals, provide performance data from a small-scale column that compares directly with the larger CsRD columns for the determination of scale-up parameters, and determine if the spent sorbent is a hazardous waste under the RCRA regulations (40 CFR 261, Subpart C). These objectives were all met, and the CsRD completed its operation. 


\subsubsection{Purpose and Scope}

This task involves the operation of an experimental unit designed and constructed to test radionuclide removal technologies during continuous operation on ORNL MVST supernatant, Savannah River HLW supernatant, and Hanford supernatant. The latter two may be simulated by adding the appropriate chemicals and/or nuclides to the MVST supernatant. The experimental unit is located in an Oak Ridge National Laboratory (ORNL) hot cell. This unit provides a test bed for investigating new technologies that become available during this program and complements the comprehensive supernatant task by using larger engineering-scale, continuous equipment to verify and expand their batch studies. It also complements the Tank Focus Area (TFA) CsRD at Oak Ridge by providing sorbent selection information, evaluation and testing of proposed sorbents, and operational experience and characteristics using the sorbent and supernatant to be used in the demonstration.

There is close cooperation with the Efficient Separations and Processing Crosscutting Program (ESP) and the TFA in order ultimately to transfer the technologies being developed to the end user. The TFA requested through ESP that we test the AEA Technology (AEAT) electrochemical-ion-exchange (EIX) system as part of this ESP program because ORNL was the only site with sufficient available supernatant for testing the multiple-cycle EIX system. The rate of removal, resin required, and regeneration requirements are important design parameters, and the loading capacity of each sorbent will help to determine the size of the column required and help define the final volume of solid waste to be disposed of.

\subsubsection{Progress}

\subsubsection{Continuation of the AEAT EIX Technology Testing}

Preparations were completed for the operation of the AEAT EIX rig to test the electrochemical elution of cesium from resorcinol-formaldehyde (R-F) resin and compare that with the standard nitric acid elution. Some of the W-29 feed previously characterized and used in the CsRD tests was used for the comparison. The R-F resin was batch tested to make sure that it was still in good condition for the EIX tests.

Using the R-F resin supplied by AEAT, cesium loadings and column volumes (CV) to a specific cesium breakthrough were comparable with those achieved with the previously tested CST from UOP. When the resins from two different cells were compared after four cycles of loading/elution/regeneration using EIX elution on one cell and standard acid elution on the other, no significant difference was noted in batch loading behavior or in physical handling or appearance. 
The operational problems were also similar for the two cases and were similar to those found in earlier column tests, with color elution, clumping, and swelling and shrinkage during the elution/regeneration steps.

In a continuation of the first series of tests, experiments were set up using both cells, each loaded with cesium using MVST W-29 feed. The experiment was conducted to determine if a difference in the effects on the resin or the efficiency of the operations existed between the elutions using the standard acid $\left(0.5 \mathrm{NHNO}_{3}\right)$ and those using the EIX method. The two cells of the system were loaded with the R-F resin prepared as one batch, and the cells were loaded from the same bottle of W-29 MVST supernatant. This supernatant has higher ${ }^{137} \mathrm{Cs}$ and potassium than the $\mathrm{W}-27$ feed used in the first series of AEAT tests but lower total cesium and much lower calcium.

The first cell was eluted with the EIX system and the second with $0.5 \mathrm{NHNO}_{3}$ over a series of four loadings and elutions, and each cell was operated in turn for each loading in the series. The resin in the cells was regenerated (converted back to the sodium form) using $1 \mathrm{~N} \mathrm{NaOH}$ after each elution. The system downstream from the cells (the lines, valves, and equipment downstream from the cells and the detector tubing) was cleaned between loadings, as well as between loadings and elutions, using $0.1 \mathrm{~N} \mathrm{HNO}_{3}$ and rinsing with water.

\subsubsection{Cell Resin Loadings}

The resin for this series of runs was prepared by weighing $7.984 \mathrm{~g}$ of R-F resin provided by AEAT (batch BSC 187) and sent to ORNL in September 1996. Five milliliters of sodium- form resin was placed in each cell, and the cells were then installed in the system. Both cells were loaded at about $7.2 \mathrm{CV} / \mathrm{h}$ based on the volume of the sodium-form resin initially placed in the cells $(4.6 \mathrm{~mL})$. Each resin loading was continued for about $65-70 \mathrm{CV}$ and then rinsed with water until the rinse stream passed the detector. The cell was then prepared for elution by either EIX or acid.

The preparations for the electrochemical elution after the first loading of cell 1 included adding $250 \mathrm{~mL}$ of $0.1 \mathrm{NHNO}_{3}$ and $250 \mathrm{~mL}$ of $0.1 \mathrm{~N} \mathrm{NaOH}$ to the anolyte and catholyte tanks, respectively. In addition, about $100 \mathrm{~mL}$ of $0.01 \mathrm{~N} \mathrm{NaOH}$ was placed in the caustic rinse tank for the cell and attached for circulation through the cell resin bed from bottom to top during the elution. The caustic rinse pump was calibrated to pump at $0.5 \mathrm{~mL} / \mathrm{min}(6.5 \mathrm{CV} / \mathrm{h})$ and was operated at that flow rate throughout the elution.

The elution of cell 2 was performed with approximately $11.5 \mathrm{CV}$ of $0.5 \mathrm{NHNO}_{3}$ followed by a deionized (DI) water rinse that continued until the rinse passed the detector. The elution was carried out in downflow as in the loading, but at $10.8 \mathrm{CV} / \mathrm{h}$. The total volume that passed through the cell during the elution was about $15-20 \mathrm{CV}$. After the elution of cell 2 , both cells were 
converted back to the sodium form with $1 \mathrm{~N} \mathrm{NaOH}$ at $14.4 \mathrm{CV} / \mathrm{h}$ for about $10 \mathrm{CV}$. Each cell was then rinsed with water and was ready for the next loading.

\subsubsection{Loading Results}

The results of the first loading of the cells corresponded very closely. Each finished the $65-70 \mathrm{CV}$ of feed at about $1 \%{ }^{137} \mathrm{Cs}$ breakthrough. The loading profiles were also close. After the elution and regeneration of both cells, the cells were again loaded with the W-29 feed stream.

By the fourth loading of cell 1 , the system continued to be plagued with problems when the pressure drop across the cell became high enough that there were concerns that the pump could not supply enough pressure to keep the flow rate at the desired level. After several CV should have passed through the system and into the fraction collector, no liquid was reaching the collector. Finally, the flow rate was increased. Even running the pump at almost twice the number of revolutions per minute did not achieve the desired $7.2 \mathrm{CV} / \mathrm{h}$ throughout the rest of the loading. After the attempted elution of the fourth loading of cell 1 , it was found that some of the supernatant was entering the catholyte chamber of the cell, rather than going through the resin. Approximately $160-190 \mathrm{~mL}$ of supernatant entered the catholyte during this loading, indicating that the membrane had a hole. The break could have resulted during attempts to fluidize the bed after the previous elution or when the resin was stirred, but no visible break was seen when the cell was disassembled. It was difficult to determine how much of the cesium in the supernatant that entered the catholyte was loaded onto the resin. The curve shows the loading based on the supernatant that passed through the cell and detector and into the fraction collector.

\subsubsection{Elution Results}

The four elutions of cell 2 were performed with $0.5 \mathrm{~N} \mathrm{HNO}_{3}$. The curves were nearly the same, and each required approximately $10-12 \mathrm{CV}$ of acid for the cesium to be removed from the resin and the cesium level to return to less than $50 \%$ of the feed level. Elutions 2 and 3 had faster returns to the baseline than either 1 or 4 . With the high drop in cell pressure, it was difficult to achieve the desired flow through the cell; however, the cesium was removed by the acid.

The first cycle of EIX elution was continued until most of the cesium was removed from the resin into the catholyte. The cesium began to show up in the catholyte after about $50 \mathrm{~min}$. The total cesium elution took more than $7 \mathrm{~h}$. During the elution, the cell current remained constant at $151 \mathrm{~mA}$. The voltage reached a peak of $\sim 51 \mathrm{~V}$ about 30-35 min after the elution started and decreased to $\sim 20 \mathrm{~V}$, where it remained during the rest of the elution. The material balance on the loading and elution showed that greater than $95 \%$ of the cesium loaded onto the resin was removed into the catholyte during the elution. 
The second and third EIX elutions were similar and required just over $3 \mathrm{~h}$ to complete. They started at 8-12 V and $151 \mathrm{~mA}$ current. Each achieved approximately 99-101\% cesium removal from the resin and began to show significant quantities of cesium in the catholyte in about 80-90 min. The voltage in both rose during the first $120 \mathrm{~min}$ and reached the maximum limit of $60 \mathrm{~V}$. The current then dropped while the voltage was at the limit. This was followed by a return to lower voltage and an increase to the maximum current $(151 \mathrm{~mA})$ after a period of 10-20 min.

For the fourth EIX elution, it was planned to reuse the catholyte from the third elution and test to see whether the cesium could be removed from the resin and passed to the catholyte as it had been when the catholyte contained more cesium. Unfortunately, some of the supernatant from the loading cycle had passed through the cation-exchange membrane into the catholyte chamber during the fourth loading. As a result, the catholyte was about $2 \mathrm{~N} \mathrm{NaNO}_{3}$ instead of $0.1 \mathrm{~N} \mathrm{NaOH}$. The extra salt apparently prevented most of the EIX elution from taking place, although the level of cesium in the catholyte stream did increase during the attempted EIX elution and about $10-15 \%$ of the loaded cesium was transferred to the catholyte stream.

The anolyte and catholyte tanks were refilled with fresh $0.1 \mathrm{~N}$ acid and base solutions, and the elution was attempted again. This time, due to the high pressure drop across the cell, no $0.01 \mathrm{~N}$ caustic was passed through the resin during the elution. The second try at the EIX elution after the fourth loading was similar to the first elution after the first loading, and the cesium was removed from the resin in a similar manner. The material balance for the fourth loading and the two attempts at elution showed that about $90 \%$ of the calculated cesium loaded was removed during the two elutions.

The results of the loadings and elutions of the two cells show the material balance on the cesium was very good on both cells for the first three loading/elution cycles. The fourth cell loading had a recovery of about $90 \%$ for both cells, which appeared to be related to the high pressure drop across the cells. At least for cell 1 , the recovery was also related to the loss of supernatant to the elution circuit during the loading cycle. It is possible that cell 2 also lost supernatant during the fourth loading cycle, but this could not be determined.

Each acid elution used about $17 \mathrm{CV}$ of $0.5 \mathrm{NHNO}_{3}$ and $17 \mathrm{CV}$ of water rinse, for a total of $34 \mathrm{CV}$. The EIX elutions used about $54 \mathrm{CV}$ of catholyte solution for each elution and $54 \mathrm{CV}$ of anolyte solution for all elutions combined.

\subsubsection{Analysis of the Resin and Cells After the Loadings}

After the completion of the loading experiments, the cells were removed from the EIX rig and examined. The resin, which was in the acid or hydrogen form, was removed from both cells by 
pipetting. The resin was not clumped or crusty, as had been expected, but was easily removed with the small-diameter pipette. The resin removed was about $4.1 \mathrm{~mL}$ from cell 1 and $4.3 \mathrm{~mL}$ from cell 2; there were considerable fines in both cells. Extra debris appeared to exist in cell 1 in addition to the resin fines, and the color of the liquid as it was removed and the resin regenerated was more brownish than in cell 2 . The pressure drop across the cells appears to have been caused by the debris and fines plugging the urethane foam plugs at the entrance and exit of each cell.

After the resin was removed from the cells, it was placed into $15-\mathrm{mL}$ graduated centrifuge tubes and regenerated with two 9-mL batches of $1 \mathrm{~N} \mathrm{NaOH}$, which were decanted between fillings. The resin was well mixed with each fill of caustic and allowed to stand for $15 \mathrm{~min}$. The resin in each tube was then rinsed three times with $10 \mathrm{~mL}$ of DI water. After the third rinse, the rinse water was checked with $\mathrm{pH}$ paper and gave a value of 12. A small sample from each cell's resin was then prepared for a batch contact test to compare the sorption capacity remaining after four cycles of loading and elution with a sample of the resin originally prepared for the run and the dry resin as received from AEAT. The wet resin samples were prepared by drying on a paper towel, adding a portion of each to 15-mL centrifuge tubes, and then weighing to determine the mass of towel-dried resin added to each tube. Ten milliliters of the same W-29 supernatant used in the experiments was added to each tube, and the tubes placed on a tilting mixer (Labquake mixer tilting at about 20 cycles per minute) for $69 \mathrm{~h}$. Each tube was then sampled through a $0.45-\mu \mathrm{m}$ filter and counted to determine the sorption for its resin.

The results indicate that no appreciable difference existed in the sorption capacity for the three different sets of resin compared with the dry untreated resin. Insufficient data were obtained in this short test to determine small differences, but no major deterioration in either resin's sorption capacity was readily apparent. Since the actual dry weight of each portion of the resin added to each tube was not available, the uncertainty in the $\mathrm{K}_{\mathrm{d}}$ is fairly large, on the order of $25 \%$. The dry weight was estimated by subjecting some dry resin to the treatments that the cell resins had received (wetting, acid, rinse, caustic, rinse, towel dry, and air dry) and estimating the ratio of towel-dried to dry resin from this process. The first sample from cell $l$ is questionable because of a problem with the determination of the weight of the resin placed in the tube. The effects of the differences between resin treatments could not be determined based on this single test.

\subsubsection{Comparisons of R-F Resin Loading}

The $\mathrm{R}-\mathrm{F}$ resin has been used in a series of tests over a 2 -year period. The resin came from three different sources, and each batch had different characteristics for cesium capacity. In addition, the supernatant used for the feed material can have a large effect on the breakthrough. The main 
difference between the two supernatants was the higher $(0.43 M$ vs $0.25 M)$ potassium concentration in the W-29 feed compared with the W-27 feed. The R-F resin is very sensitive to the potassium concentration.

Changes in the resin loadings due to differences in cell geometry between the columns and cells were not apparent in either series of EIX tests for the first loadings. For second and subsequent loadings of the EIX cells, the rectangular cross section of the cells provided a better opportunity for the $\mathrm{R}-\mathrm{F}$ resin to bridge across the corners and, with the clumping tendency of the R-F, made maintenance of a fully packed and utilized resin bed more difficult. Some of these same tendencies were also observed in previous column tests using W-27 supernatant and R-F resin in multiple loading/elution tests. Some plugging of the beds or the inlet and outlet resin-retention plugs was apparent after the second and, especially the third, cycle. Whether this was due to resin degradation or supernatant component precipitation is not known, although this supernatant was filtered before use through a $0.45-\mu \mathrm{m}$ filter and several liters had also been used without incident during a previous experiment in a circular cross-sectional column containing the UOP IE-911 ${ }^{\circledR} \mathrm{CST}$.

A comparison of the sequential loading results with previous tests, both with simulants and with supernatants, showed that this series did not result in a consistent cesium loading from start to finish as in the earlier tests with either acid or EIX elutions. In both sets of tests, the loading curves were consistent in the location of the upturn in the curve and were within $20 \%$ of the $50 \%$ breakthrough CV for all loadings under the same conditions for the same resin. As mentioned earlier, problems with flow patterns and plugging contributed to the poor loading curves because the batch tests conducted on the used resins gave very similar loadings to the as-received resins.

\subsubsection{EIX Elution Efficiencies}

The electrical efficiency of the elutions using EIX was compared by AEAT for simulant solutions using a cell with the same dimensions. The results showed that elution at $50-\mathrm{V}$ (vs $30-V)$ cell potential gave a much improved elution profile and reduced the time required for elution by more than half. Consequently, $60 \mathrm{~V}$, believed to be even better, was used in all tests with the actual waste supernatant. The AEAT work also showed that the current required was almost independent of the voltage or current levels used in the elution, requiring about $800 \mathrm{C}$ (coulombs) for the simulant tests at $50 \mathrm{~V}$ for $100 \%$ cesium removal from the R-F resin.

In the experiments with actual W-27 supernatant, the charge passed for the elutions was $2523 \mathrm{C}$ and $1826 \mathrm{C}$ for the first elution for cell 2 and the first and third elutions for cell 1 , respectively. [For the W-29 experiments, $4000 \mathrm{C}$ was required for the first elution, $1823 \mathrm{C}$ for the second, and $1906 \mathrm{C}$ for the third.] The fourth elution was completed after changing the catholyte 
when it had become contaminated by the supernatant solution; $3028 \mathrm{C}$ was required for elution to the point at which no more cesium was removed. The second and third elutions required about the same amount of time as the AEAT simulant but about twice the charge transfer. The first elution, with the greatest requirement for current, was probably loaded with extra calcium from some of the earlier W-27 feed still remaining in the tanks or piping and gave results that were similar to those from the earlier W-27 experiments. The supernatant samples that passed through the resin bed were checked for the ratio of ${ }^{137} \mathrm{Cs}$ to ${ }^{134} \mathrm{Cs}$ and gave results that were consistent with a mix of W-27 and W-29 supernatants. The later three experiments had results consistent with the analysis of the W- 29 feed supernatant.

Compared with the AEAT simulant tests, the tests using the W-27 supernatant required a long induction period before cesium began to be removed from the resin and appear in the catholyte solution. The reason has not been determined but appears to be related to the high calcium level in the W-27 feed solution, which loaded on the resin and had to be eluted before the cesium would elute. When W-29 supernatant that contained about 1 ppm calcium was used, the cesium elution began within 90-120 min or less, which was similar to the period observed in the AEAT simulant tests and much improved over the 500-600 min required for the W-27 supernatant that contained about $40 \mathrm{ppm}$ calcium. The acid elutions were very similar to previous R-F elutions using $0.5 \mathrm{~N}$ $\mathrm{HNO}_{3}$. The curves were not very steep and tended to tail for many $\mathrm{CV}$ after the peaks, both when acid was continued and when water rinse was used after the peak cesium concentration was reached.

The secondary waste produced by the two elution methods included the acid elution solution, the initial column rinse ("sweetening off"), the elution with acid, the water rinse, caustic regeneration, and final rinse. This totaled approximately $35 \mathrm{CV}$ for each elution. For EDX elutions, it included the anolyte and catholyte solutions, the cell rinse, the dilute caustic used during the elution to rinse the bed, and the regeneration solution and final rinse. The anolyte and cell rinse solutions were reused for subsequent elutions; therefore, the catholyte, regenerent solutions, and rinses totaled about $50 \mathrm{CV}$. The catholyte solution can also be reused, so this number would drop significantly and the amount used for each elution would generally be that of the two rinses and the regeneration solution, or about $15 \mathrm{CV}$.

\subsubsection{Conclusions}

The results of the two sets of experiments described for EIX cell elution tests showed that the EIX system will remove cesium from loaded R-F resin to the same extent as elution with $0.5 \mathrm{MHNO}_{3}$. The biggest difference between the experiments performed by AEAT using simulant and the tests described in this report is the composition of the feed materials to the cells. 
The supernatants that were used (MVST W-27 and W-29) contained much less total cesium than the AEAT simulant; however, they contained many trace materials that were not contained in the simulant and that greatly affected the loading and especially the EIX elutions. The first set required up to $10 \mathrm{~h}$ for the elution to be completed, but only $3 \mathrm{~h}$ was required for the second and third EIX elutions in the second set and as little as $90 \mathrm{~min}$ for simulants. In addition, the simulants required much less total charge transfer than the actual supernatants.

The second set of experiments was intended to determine if the EIX system would protect the resin better than the acid elution normally used for R-F resin. The results were not definitive. In addition, the R-F resin appeared to undergo some degradation during the course of the loadings. In each cell, the resin appeared to clump, bridge, and generally be difficult to manage in the rectangular cross-sectional cells.

Although the R-F resin appeared to behave satisfactorily in simulant situations, during operation with the supernatants from the MVSTs at ORNL, problems developed during each set of tests that required more than a single loading and elution. None of these were related to either the acid or EIX elutions. In these tests, in addition to colored solutions leaving the resins during changes in the electrolyte content of the liquids in contact with the resin, clumping and other problems resulted in operational difficulties that ended in high pressure drops across the cells after the third and fourth loadings of both cells. Because of these problems, R-F resin would not be the best choice for cesium removal from the MVSTs at ORNL. With a proper elutable resin, the EIX process appears to be workable for cesium removal from the MVSTs. Other resins may be workable for other cations in solution in other waste streams. Under the right conditions, a concentrated waste stream containing only the cations eluted from the resin could be produced. The trade-off appears to be between process complexity and cell construction technology versus secondary waste production.

\subsection{DEVELOPMENT AND TESTING OF INORGANIC SORBENTS (J. L. Collins and K. K. Anderson)}

Contact: J. L. Collins

Telephone: (423)574-6689

Internet: collinsjl@ornl.gov

Summary: Development of a cesium-specific spherical inorganic sorbent for the treatment of acidic high-salt waste solutions was initiated. Acid-side treatment is important at Idaho National Engineering and Environmental Laboratory (INEEL). A composite microsphere of zirconium monohydrogen phosphates (ZrHP) embedded with ammonium molybdophosphate (AMP) was chosen as the sorbent for development. Optimization involves empirically determining the amount 
of AMP that can be embedded in the microspheres to maximize cesium loading from acidic supernatant with high salt concentrations. A total of ten preparations have been made, and cesium-removal batch tests were conducted with MVST W-27 supernatant that was acidified with nitric acid to a $\mathrm{pH}$ of 0.8 . The dry-weight percentages of AMP for these preparations were in the range of 30 to 60 . The best distribution ratios (D values) for the wet and for the air-dried $\mathrm{ZrHP}$ AMP microspheres were $-16,100$ and $39,300 \mathrm{~mL} / \mathrm{g}$, respectively, with 98.7 and $99.5 \%$ of the cesium being removed.

\subsubsection{Purpose and Scope}

The general objectives of this task are to develop, prepare, and test new and unique inorganic ion exchangers made as microspheres by the internal gelation process to remove fission products, actinides, and other metals (such as the RCRA metals) from waste streams occurring at the various DOE sites. Inorganic sorbents made in the engineered form as microspheres are much more column usable than the powder or granular forms that are commercially available. The focus of this program is to develop microspheres of materials that have already been shown to be highly effective as cesium and strontium sorbents.

The development of cesium-specific spherical sorbents for treatment of acidic high-salt waste solutions was initiated in FY 1998. Acid-side treatment is important at INEEL and could become important if acidic sludge washing were to become a treatment option at Hanford, Savannah River, or Oak Ridge. The cesium-selective inorganic sorbent chosen for making microspheres was $\mathrm{ZrHP}$ embedded with AMP. AMP is known to be a very effective sorbent for removing cesium from waste streams over a wide range of acidity and salinity and has very rapid loading kinetics. The cesium can also be eluted from AMP with ammonium salt solutions. AMP cannot be used as a sorbent at $\mathrm{pH}$ values above 7 because it decomposes. In the $\mathrm{pH}$ range of 1 to $7, \mathrm{ZrHP}$ is also a very effective sorbent for removing $\mathrm{Cs}$, $\mathrm{Sr}$, Th, U(VI), $\mathrm{Pu}$ (IV), $\mathrm{Am}(\mathrm{III}), \mathrm{Hg}$, and $\mathrm{Pb}$ from streams of lower ionic concentrations. The composite microsphere, as a totally inorganic sorbent, has the advantage of being stable in high radiation fields. ZrHP-AMP microspheres loaded with cesium could be stored for indefinite periods, or the cesium could be desorbed from the sorbent with ammonium salts solutions.

\subsubsection{Progress}

Experimental work was initiated to develop a composite microspherical sorbent of ZrHP embedded with fine particles of AMP, which is currently being optimized for the removal of cesium from acidic supernatants with high salt concentrations. Optimization involves empirically determining the amount of AMP that can be embedded in the microspheres to maximize cesium

loading from acidic supernatant with high salt concentrations. AMP powders prepared by two 
different methods and AMP powder obtained from Bio-Rad Laboratories were used in the preparations. Ten preparations of AMP-hydrous zirconium oxide microspheres were made and converted to AMP-ZrHP with phosphoric acid. Six of the preparations were made using the Bio-Rad AMP, which proved to be the most effective in removing the cesium.

Cesium-removal batch tests were conducted with samples of undried and air-dried ZrHPAMP microspheres. The dry-weight percentages of AMP for these preparations were in the range of 30 to 60 . MVST W-27 supernatant that was acidified with nitric acid to a $\mathrm{pH}$ of 0.8 was used. The major constituents of the acidified supernatant were sodium $(4.86 M)$, potassium $(0.26 M)$, and $\mathrm{NO}_{3}{ }^{-}(5.34 M)$. Cold cesium was also added to increase the cesium concentration from about $1 \mathrm{mg} / \mathrm{L}$ to $100 \mathrm{mg} / \mathrm{L}$. The concentration of ${ }^{137} \mathrm{Cs}$ was about $8.5 \mathrm{mCi} / \mathrm{L}$. For comparison, similar tests were conducted with a composite sorbent, AMP-polyacrylonitrile (PAN), which was obtained from F. Sebesta at the Czech Technical University in Prague, Czech Republic. This sorbent is composed of AMP powder bound in an organic polymer of PAN. Duplicate tests were conducted using a ratio of volume of supernatant (in milliliters) to mass of dry sorbent (in grams) of 200 and a mixing time of $\sim 24 \mathrm{~h}$. The weight ratio of wet microspheres to air-dried microspheres ranged from 4.6 to 5.6 and was 4.2 for the AMP-PAN. The AMP-PAN was tested as received in the undried form. The average D value for the PAN-AMP samples was $\sim 35,600 \mathrm{~mL} / \mathrm{g}$. About $99.4 \%$ of the cesium was removed. The best D values for the wet and air-dried ZrHP-AMP microspheres were $\sim 16,100$ and $39,300 \mathrm{~mL} / \mathrm{g}$, respectively, with 98.7 and $99.5 \%$ of the cesium being removed.

\section{PROCESS CHEMISTRY AND THERMODYNAMICS}

\section{E. C. Beahm}

\subsection{SLUDGE TREATMENT STUDIES (E. C. Beahm, T. A. Dillow, R. D. Hunt, and C. F. Weber)}

Contact: E. C. Beahm

Telephone: (423) 574-6851

Internet: beahmec@ornl.gov

Summary: Gel-like phosphate solids may form in process solutions from caustic treatment of sludge from Hanford underground storage tanks. A model was developed to provide guidance on how caustic leaching and associated water washing of sludge will have to be carried out to avoid the formation of these solids. The concentration of sodium hydroxide is the main force affecting solid formation in solutions containing phosphate and fluoride. 


\subsubsection{Purpose and Scope}

A particular objective of sludge treatment studies is to obtain a low-volume high-activity waste stream and a high-volume low-activity waste stream. Two aspects of sludge treatment should be well delineated and predictable: (1) the distribution of chemical species between aqueous solutions and solids and (2) potential problems due to chemical interactions that could result in process difficulties or safety concerns.

\subsubsection{Progress}

Previous experimental studies have demonstrated that phosphate-containing solids may form in process solutions from ESW. A model of the sodium phosphate-sodium fluoride-sodium hydroxide-water system was developed to provide guidance on how ESW will have to be carried out to avoid the formation of solids containing phosphate. The model indicated that the concentration of sodium hydroxide is the main force affecting solid formation in solutions containing phosphate and fluoride.

Two test sequences were carried out to evaluate the formation of phosphate-containing solids on cooldown and to assess our model for the sodium phosphate-sodium fluoride-sodium hydroxide-water system. In one series of tests, three samples were prepared:

\begin{tabular}{|c|c|c|c|}
\hline Sample & Na phosphate $(m)$ & $\operatorname{NaF}(m)$ & $\mathrm{NaOH}(m)$ \\
\hline A & 0.28 & 0.05 & 3.0 \\
\hline B & 0.20 & 0.10 & 3.0 \\
\hline $\mathrm{C}$ & 0.08 & 0.20 & 3.0 \\
\hline
\end{tabular}

In comparison with the concentrations in these samples, sludge from Hanford tank T-104 contains $0.78 \mathrm{~mol} / \mathrm{kg}$ of phosphate and greater than $0.45 \mathrm{~mol} \mathrm{~F} / \mathrm{kg}$. This means that the phosphate and fluoride concentrations in the samples were within the range that could occur in ESW. Three samples were heated at $95-100^{\circ} \mathrm{C}$ for $4 \mathrm{~d}$, and no solids were seen. The temperature was then lowered to $52^{\circ} \mathrm{C}$ over a period of $25 \mathrm{~h}$. No solids were seen during this cooldown, but solids resembling egg whites floating in solution were seen after $5 \mathrm{~h}$ at $52^{\circ} \mathrm{C}$. The temperature was further decreased to $25^{\circ} \mathrm{C}$ over a 26 -h period. The floating egg white-like material increased in size and amount and adhered to the walls of the sample container. Crystalline solids formed in the samples after they were at $20-22^{\circ} \mathrm{C}$ for $2 \mathrm{~d}$. When Sample A was inverted after 2 weeks at this 
ambient temperature, it totally fused into a solid mass with no liquid. This most likely occurred because the liquid in Sample A was supersaturated and, when the sample was inverted, it came into contact with small crystals that seeded the precipitation. The sodium phosphate fluoride hydrate that forms in these solutions has 19 waters of hydration. Thus, when crystallization occurs, liquid water is put into the solid.

In the other test sequence, the samples were $5 \mathrm{~m} \mathrm{NaOH}$. The tests were run at $25^{\circ} \mathrm{C}$. In these tests, solid formation was seen at concentrations as low as $0.015 \mathrm{~m}$ sodium phosphate and $0.02 \mathrm{~m}$ sodium fluoride. This means that in leachates with this relatively high $\mathrm{NaOH}$ concentration, most of the phosphate and fluoride would form solids. Eighteen samples were examined by scanning electron microscopy and X-ray diffraction (XRD) to evaluate a model of phosphate solid formation. At both $3 m$ and $5 m \mathrm{NaOH}$, the model performed well, except at relatively low fluoride concentrations and relatively high phosphate concentrations. Additional tests are being run with solutions containing $1 \mathrm{~m} \mathrm{NaOH}$ to assess the low concentration limits at which solids form.

\subsection{THERMODYNAMICS AND KINETICS OF ENERGY-RELATED MATERIALS (E. C. Beahm and R. D. Hunt)}

Contact: E. C. Beahm

Telephone: (423) 574-6851

Internet: beahmec@ornl.gov
Contact: R. D. Hunt

Telephone: (423) 574-5481

Internet: huntrd@ornl.gov

Summary: Experimental work on the collaboration with Dr. Gennady Voronin of Moscow State University has been completed as directed by DOE. The goal of this effort was to determine the solidification conditions of yttrium, barium, and copper oxides from their melts. These conditions include temperature, partial oxygen pressure, chemical composition of the melt, and chemical composition of the growing solids. Differential thermal analysis (DTA)/thermogravimetric analysis (TGA) and hydrogen reduction have been used to determine the oxygen contents of melts from $\mathrm{YBa}_{2} \mathrm{Cu}_{3} \mathrm{O}_{n}(1: 2: 3: n), 1: 2: 3: n+\mathrm{BaCuO}_{2}(1: 3: 4: n)$, and $1: 2: 3: n+4.3 \mathrm{CuO}(1: 2: 7.3: n)$ at partial oxygen pressures ranging from 0.1 to $0.000006 \mathrm{MPa}$. A manuscript, which describes phase transitions and oxygen content in the melts of 1:2:3:n and 1:3:4: $n$, has been submitted to Physica $C$.

Several attempts to determine the oxidation state of copper in superconducting 1:2:3: $n$ have been made. However, a comprehensive evaluation of all potential oxidation states at different oxygen stoichiometries has not been made. While $1: 2: 3: n$ is usually expressed in terms of the formula $\mathrm{YBa}_{2} \mathrm{Cu}^{+2}{ }_{2+2 x} \mathrm{Cu}^{+3}{ }_{1-2 x} \mathrm{O}_{7-x}(0 \leq x \leq 0.5)$, it is possible that all of the copper in 1:2:3: $n$ is $\mathrm{Cu}^{+2}$ or a combination of $\mathrm{Cu}^{+}$and $\mathrm{Cu}^{+2}$ and that some oxygen is present in the form of peroxide. Our current study used both oxidizers and reductants to determine the proper representation of 1:2:3:n at its different oxygen stoichiometries. Samples of $\mathrm{YBa}_{2} \mathrm{Cu}_{3} \mathrm{O}_{6}, \mathrm{YBa}_{2} \mathrm{Cu}_{3} \mathrm{O}_{6.36}, \mathrm{YBa}_{2} \mathrm{Cu}_{3} \mathrm{O}_{6.54}$, and $\mathrm{YBa}_{2} \mathrm{Cu}_{3} \mathrm{O}_{6.9}$ have been dissolved in hydrochloric acid solutions with potassium permanganate (strong oxidizer) or sodium thiosulfate (strong reductant). The solutions were then neutralized. Since each oxygen stoichiometry can be represented in three distinct ways, key components from each possible formulation, with the exception of the formulas with $\mathrm{Cu}^{+3}$, were treated in the same 
manner as the 1:2:3: $n$ samples. An analysis indicates that the best representations for $\mathrm{YBa}_{2} \mathrm{Cu}_{3} \mathrm{O}_{6}$ and $\mathrm{YBa}_{2} \mathrm{Cu}_{3} \mathrm{O}_{6.36}$ are $\mathrm{YBa}_{2} \mathrm{Cu}_{2}{ }^{+2} \mathrm{Cu}^{+} \mathrm{O}_{6}{ }^{-2}$ and $\mathrm{YBa}_{2} \mathrm{Cu}_{2.72}{ }^{+2} \mathrm{Cu}_{0.28}{ }^{+} \mathrm{O}_{6.36}{ }^{-2}$, respectively. The results with $\mathrm{YBa}_{2} \mathrm{Cu}_{3} \mathrm{O}_{6.64}$, and $\mathrm{YBa}_{2} \mathrm{Cu}_{3} \mathrm{O}_{6.9}$ imply the presence of $\mathrm{Cu}^{+3}$. Preparation of a manuscript on these findings is under way, and this evaluation of the oxidation states of copper will be concluded as soon as the paper has been accepted for publication.

\subsubsection{Purpose and Scope}

The objective of this program is the measurement and interpretation of chemical thermodynamics in applied-technology ceramic systems. Presently, this project concerns phase equilibria and thermodynamics of the $\mathrm{R}-\mathrm{Ba}-\mathrm{Ca}-\mathrm{Cu}-\mathrm{O}$ system, with $\mathrm{R}$ representing $\mathrm{Y}, \mathrm{La}, \mathrm{Pr}$, and $\mathrm{Nd}$. Emphasis is placed on the phase fields that include the superconducting compounds.

\subsubsection{Progress}

\subsubsection{Solidification of the Y-Ba-Cu-O System}

Experimental work on the collaboration with Dr. Gennady Voronin of Moscow State University has been completed as directed by DOE. Three of the seven proposed compositions were evaluated. The goal of this joint effort was to determine the solidification conditions of yttrium, barium, and copper oxides from their melts. These conditions included temperature, partial oxygen pressure, chemical composition of the melt, and the phase and chemical composition of the growing solids. The liquidus and solidus surfaces in the $\mathrm{Y}-\mathrm{Ba}-\mathrm{Cu}-\mathrm{O}$ system can be determined in terms of temperature, composition, and oxygen chemical potential.

The phase transitions and oxygen content in the melts of $1: 2: 3: n$ and 1:3:4:n at partial oxygen pressures of $0.1,0.01,0.001,0.0001$, and $0.00006 \mathrm{MPa}$ have been determined experimentally. A manuscript, which describes these results, has been submitted to Physica $C$.

\subsubsection{Oxidation States of Copper and Oxygen in 1:2:3:n}

With the discovery of $1: 2: 3: n$, several attempts to determine the oxidation state of copper in superconducting 1:2:3: $n$ have been made. However, a comprehensive evaluation of all potential oxidation states at different oxygen stoichiometries has not been made. While 1:2:3:n is usually expressed by the formula $\mathrm{YBa}_{2} \mathrm{Cu}^{+2}{ }_{2+2 x} \mathrm{Cu}^{+3}{ }_{1-2 x} \mathrm{O}_{7-x}(0 \leq x \leq 0.5)$, it is possible that all of the copper in $1: 2: 3: n$ is $\mathrm{Cu}^{+2}$ or a combination of $\mathrm{Cu}^{+}$and $\mathrm{Cu}^{+2}$ and that some oxygen is present in the form of peroxide. Our current study uses both oxidizers and reductants to determine the proper representation of 1:2:3:n at its different oxygen stoichiometries.

As reported earlier, samples of $\mathrm{YBa}_{2} \mathrm{Cu}_{3} \mathrm{O}_{6}, \mathrm{YBa}_{2} \mathrm{Cu}_{3} \mathrm{O}_{6.36}, \mathrm{YBa}_{2} \mathrm{Cu}_{3} \mathrm{O}_{6.64}$, and $\mathrm{YBa}_{2} \mathrm{Cu}_{3} \mathrm{O}_{6.9}$ have been dissolved in solutions of hydrochloric acid and potassium permanganate, a strong oxidizer. The solutions were then reduced with sodium thiosulfate. Recently, similar experiments 
were performed with the various forms of $\mathrm{YBa}_{2} \mathrm{Cu}_{3} \mathrm{O}_{x}$, which were dissolved in solutions of hydrochloric acid and sodium thiosulfate, a strong reductant. The solutions were then oxidized with potassium permanganate. Key components from each possible formulation, with the exception of the formulas with $\mathrm{Cu}^{+3}$, were treated in the same manner as the 1:2:3:n samples. The recent results confirmed the earlier ones, and they indicated that the best representations for $\mathrm{YBa}_{2} \mathrm{Cu}_{3} \mathrm{O}_{6}$ and $\mathrm{YBa}_{2} \mathrm{Cu}_{3} \mathrm{O}_{6.36}$ are $\mathrm{YBa}_{2} \mathrm{Cu}_{2}{ }^{+2} \mathrm{Cu}^{+} \mathrm{O}_{6}{ }^{-2}$ and $\mathrm{YBa}_{2} \mathrm{Cu}_{2.72}{ }^{+2} \mathrm{Cu}_{0.28}{ }^{+} \mathrm{O}_{6.36}{ }^{-2}$, respectively. The results with $\mathrm{YBa}_{2} \mathrm{Cu}_{3} \mathrm{O}_{6.64}$ and $\mathrm{YBa}_{2} \mathrm{Cu}_{3} \mathrm{O}_{6.9}$ imply the presence of $\mathrm{Cu}^{+3}$. Preparation of a manuscript on these findings is under way, and this evaluation of the oxidation states of copper will be concluded as soon as the paper has been accepted for publication. However, if this task continues in its present direction, future experiments will involve different oxidizers and reductants, as well as different superconductors with copper.

\subsubsection{Collaborations}

This project has completed its collaborative efforts with two other Basic Energy Sciences (BES) projects. This project has manipulated the oxygen content in five large 1:2:3:n crystals for the BES project, which is led by Herbert Mook, Pengcheng Dai, and Mohana Yethiraj. After the crystals have reached the desired oxygen content, magnetic dynamics experiments, which permit direct observation of the superconducting band, are performed on the underdoped 1:2:3:n crystals. A manuscript, which describes our recent magnetic dynamic results, has been submitted to Physical Review Letters.

The second collaboration involved the BES project, which is led by Mariappan Paranthaman and Amit Singhal. After the 1:2:3: $n$ had been prepared through the sol-gel technique, the sample was analyzed with our DTA/TGA analysis apparatus. Since our task has performed the same experiments on 1:2:3:n samples that were prepared by conventional means, a direct comparison of the different sample preparations can be made. A manuscript describing these results is undergoing internal technical review. 


\section{SEPARATIONS AND MATERIALS SYNTHESIS}

\section{W. DePaoli}

\subsection{CHEMICAL AND PHYSICAL PRINCIPLES IN MULTIPHASE SEPARATIONS (D. W. DePaoli, C. Tsouris, and X. Zhang)}

Contact: D. W. DePaoli

Telephone: (423) 574-6817

Internet: ddi@ornl.gov

Summary: Fundamental studies of multiphase systems, particularly those that explore the use of electromagnetic fields to enhance transport processes, are continuing. Progress has been made in several areas, including (1) drop deformation and breakup from a capillary tube in liquid-air and liquid-liquid systems, (2) wetting and stability of drops on solid surfaces, (3) electric field simulations, and (4) spraying and mixing in electrohydrodynamic (EHD) flows.

\subsubsection{Purpose and Scope}

This program is comprised of several fundamental studies that explore transport processes in multiphase separations, with particular emphasis placed on the application of electromagnetic fields for enhancement. Experimental, theoretical, and computational methods are employed to investigate the effect of electromagnetic fields on transport processes in liquid-liquid, gas-liquid, and solid-liquid systems. This work will provide information necessary to devise novel means to dramatically improve transport rates in these systems and, thus, will have widespread benefit for separations processes such as solvent extraction and distillation as well as applications in environmental and biotechnology areas. The areas of current focus are (1) interface deformation and breakup, including electrostatic spraying (both "normal" and "inverse"), drop formation, drop oscillations, stretching liquid bridges, and drop impact; (2) interactions and coalescence of drops; and (3) enhancement of transport processes through EHD flows.

\subsubsection{Progress}

\subsubsection{Drop Deformation and Breakup}

Work is continuing on simulating the dynamics of drop deformation and breakup from a capillary tube into another immiscible liquid using volume-of-fluid and continuous-surface-force methods. Extensive computations have been carried out to simulate drop formation in liquid-liquid systems at different physical conditions. This study is of particular importance in exploring the dynamic effects of an ambient fluid on drop formation. Moreover, the model predicts the generation and fate of satellites, which are important in many practical applications, including spray-coating and ink-jet technologies. Two noteworthy results of this work are that flow regimes that result in 
no satellite formation have been discovered, and very good agreement with our experimental results was found. A manuscript reporting the results has been submitted to the Journal of Fluid Mechanics.

\subsubsection{Wetting and Stability of Drops on Solid Surfaces}

A fundamental study is conducted to understand and improve the wettability and stability of liquid drops on solid surfaces. This work is conducted in collaboration with Professor R. M. Counce of The University of Tennessee and his student, B. A. Starkweather. The capability of solutions containing different surfactants and having varied $\mathrm{pH}$ values to remove oil or organic contaminants from solid surfaces is investigated, with focus on adsorption dynamics of surfactant on oil drops of different volumes. The research is of significant importance in industrial and environmental cleaning and degreasing and in oil-recovery processes. A manuscript reporting the results is in preparation for submission to the Journal of Colloid and Interface Science.

\subsubsection{Spraying and Mixing in Electrohydrodynamic Flows}

Work on the formation of microbubbles under the influence of electric fields was continued. This work has been summarized in a paper titled "Pumping, Spraying and Mixing of Fluids by Electric Fields," which has been submitted for publication. Continued studies of EHD mixing have focused on measurement of current under different operating conditions. Preliminary results have shown interesting variability of current, which depends both on the continuous phase fluid and the applied voltage. Communications have been initiated with L. Hively and coworkers of the ORNL Engineering Technology Division to determine if their nonlinear data analysis tools can be used to understand and/or control EHD mixing.

\subsection{NUCLEATION, GROWTH, AND TRANSPORT PHENOMENA (M. Z.-C. Hu, C. H. Byers, and G. Miller)}

Contact: M. Z.-C. Hu

Telephone: (423) 574-8782

Internet: i5h@ornl.gov

Summary: Progress has been made in several aspects of synthesis, characterization, application, and processing of ultrafine particles and advanced ceramic materials. Two new methods for materials production have been developed. These methods have been selected for patent application filings; in addition, several nondisclosure agreements are currently being pursued by the Office of Technology Transfer. A collaborative effort with the Nanophase Materials Research Center at the University of Idaho and the High Temperature Materials Laboratory (HTML) at ORNL has been initiated on combustion synthesis of nanocrystalline precursor powders. 


\subsubsection{Purpose and Scope}

This materials sciences research program involves fundamental studies of chemically reactive systems for synthesis of ultrafine (particularly nanosized), monodispersed particles (i.e., oxide ceramic precursor powders). A primary goal is the understanding of the mechanisms, kinetics, and thermodynamics of nucleation and particle growth under controlled sol-gel and chemical processing conditions.

Our current emphasis lies with the chemistry, reaction engineering, colloidal/interfacial sciences, and materials sciences in three major wet-chemical systems: (1) homogeneous precipitation in inorganic salt solutions of mixed solvent; (2) forced hydrolysis via hydrothermal processing of inorganic salt aqueous solutions; and (3) acid- or base-catalyzed hydrolysis and condensation of organometallic compounds (such as alkoxides) in water-alcohol solutions. Experiments utilize several specially developed techniques, including real-time dynamic light scattering, rapid-mixing flow cell coupled with Fourier transform infrared and small-angle X-ray scattering (SAXS), as well as high-temperature XRD, electron microscopy, Raman spectroscopy, and electrostatic spraying.

It is anticipated that the results of this work will have significant impacts upon development of advanced materials such as nanoscale and nanophase ceramics that have dramatically improved properties over traditional "coarse-grained" ceramics. These advanced ceramics are potential candidates as structural ceramics, electroceramics, catalysts, nanocrystalline thin films, coatings, and nanostructured inorganic membranes.

\subsubsection{Progress}

A technique that utilizes dielectric tuning.of mixed-solvent solutions of inorganic salts has been well established for synthesis of zirconia and titania monodispersed particles. In addition, a two-stage process (i.e., dielectric tuning plus hydrothermal reactions) was developed for producing barium titanate powders, which are electroceramics of tremendous industrial importance. During this reporting period, two invention disclosures have been prepared and selected (with high priority) for filing as patent applications. A significant number of industrial requests for information on the new methods have been received; several nondisclosure agreements are currently being pursued by the Office of Technology Transfer.

A collaborative effort was initiated with the Nanophase Materials Research Center at the University of Idaho. In this work, a different approach (i.e., autoignition or combustion synthesis) was used for production of nanocrystalline precursor powders. This process had its origin in rocket propellant technology and utilizes oxidizers (e.g., metal salts) and "fuels" (typically organic 
compounds such as urea and alanine). When properly optimized, high temperatures are generated by the redox reactions between decomposition products of the oxidizer and the fuel. The "burning" mixtures generate a large amount of gas in a very short period of time, leading to the production of very fine particulates. The process is controlled by such parameters as heating rate, stoichiometry, and choice of fuel. Four samples of barium strontium titanate powders were prepared under various synthesis conditions using the equipment at the University of Idaho. Our main research goal is to understand how the synthesis conditions affect the crystallization and phase transformations of these ceramics. The four barium strontium titanate samples were studied using high-temperature XRD at the ORNL HTML facility. The spectra data are under analysis.

\subsection{PHASE EQUILIBRIA MODIFICATION BY ELECTRIC FIELDS (C. Tsouris, D. W. DePaoli, X. Zhang, and K. D. Blankenship)}

Contact: C. Tsouris

Telephone: (423) 241-3246

Internet: tq9@ornl.gov

Summary: Fundamental studies are being undertaken that explore the use of electric fields to modify phase equilibria in multiphase separations processes. Experimental systems have been assembled and are currently used to investigate transport and thermodynamic effects of electric fields on vapor-liquid and liquid-liquid systems. Batch-distillation, vapor-liquid-equilibrium(VLE), liquid-liquid-equilibrium, and vapor-pressure experiments are in progress, using various liquid mixtures of polar-nonpolar, polar-polar, and nonpolar-nonpolar components. The results obtained to date show that electric fields have an effect on the VLE of some systems.

\subsubsection{Purpose and Scope}

The primary objective of this project is to enhance separations of mixtures by applying an electric field across an interface between two phases. Enhancement in separation may be caused either by increasing transport rates through the interface or by changing the phase equilibria. Electric fields have been known to interact with charge carriers, such as ions and electrons, leading to higher mass- and heat-transfer rates, fluid atomization, mixing, and pumping, which are transport phenomena. In contrast, the effects of electric fields on the behavior of noncharged molecules and the macroscopic thermodynamic behavior of the system are examined in this project. The behavior of various types of molecules under the influence of electric fields and macroscopic effects of electric fields on such properties as dielectric constant and phase equilibria are investigated. 


\subsubsection{Progress}

Experimental systems have been assembled and used for vapor-liquid and liquid-liquid studies under electric fields. Various liquid mixtures of polar-nonpolar, polar-polar, and nonpolarnonpolar components have been used in these experiments. The results of these experiments have been summarized in a paper submitted for publication in Separation Science and Technology. During this quarter, experiments with mixtures of water and isopropanol have been conducted. In these experiments, the focus was to investigate the effect of electrode geometry on the electric current and the VLE concentrations. Electrodes of various shapes have been tested with isopropanol and water. The VLE apparatus was modified so that the various electrodes could be introduced in the system. It was found that when the electrodes have sharp points, the current increases rapidly with applied voltage. The effect of electric current on the VLE concentration is currently being investigated using the modified VLE apparatus.

\subsection{MAGNETIC-SEEDING FILTRATION(D. W.DePaoli, C.Tsouris, M. R. Chattin, and J. T. Shor)}

Contact: D. W. DePaoli

Telephone: (423) 574-6817

Internet: ddi@ornl.gov

Summary: Efforts are under way to distribute the results of this project in a timely manner through peer-reviewed publications; two manuscripts were submitted to journals this quarter. In addition, an invention regarding the production of magnetic seed particles has generated industrial interest.

\subsubsection{Purpose and Scope}

This project is focused on the development of magnetic-seeding filtration for the enhanced removal of magnetic and nonmagnetic particulates from DOE waste liquids. The technology involves the addition of a small amount of magnetic seed particles (such as naturally occurring iron oxide) to a waste suspension, followed by magnetic filtration. This technology is applicable to a wide range of liquid wastes, including groundwater, process waters, and tank supernatants.

\subsubsection{Progress}

With the carryover funding remaining in this EM-50 project, efforts are under way to distribute the results in a timely manner through peer-reviewed publications. Two manuscripts were submitted to journals this quarter. In addition, a subject invention disclosure was completed 
regarding the production of magnetic seed particles. A commercial supplier of magnetic particles has expressed interest in this invention. We will continue to pursue transfer of this technology.

\subsection{ELECTROSTATIC OZONATION (C. Tsouris, D. W. DePaoli, S. Yiacoumi, and W.-T. Shin)}

Contact: C. Tsouris

Telephone: (423) 241-3246

Internet: tq9@ornl.gov

Summary: The enhancement of oxidation of organic pollutants in aqueous solutions by using electric fields to form microbubbles containing ozone is investigated in this task. An experimental apparatus for ozonation studies has been set up. Included in this setup are the following: (1) ozone generation from air or oxygen; (2) ozone spraying in an aqueous phase containing an organic solute, such as phenol, by means of an electric field; and (3) collection of gas and liquid samples for chemical analysis. Preliminary results show an enhancement in oxidation rate for electrostatically generated microbubbles, as compared with conventional bubble diffusers.

\subsubsection{Purpose and Scope}

The primary objective of this project is to enhance the efficiency of ozonation processes by inverse electrostatic spraying. Ozone is a strong oxidant of organic molecules with fast reaction kinetics; thus, in most cases, ozonation is a mass-transfer-limited process, which can be improved by decreasing the size of ozone-containing gas bubbles. Introduction of ozone in the form of microbubbles will enhance efficiency both by increasing the surface area per unit volume between the gas and liquid phases and by increasing the gas volume fraction (since smaller bubbles rise at a lower velocity than larger bubbles). This project is aimed at applying the knowledge gained in our fundamental studies of inverse electrostatic spraying to develop an efficient means for production of ozone-containing microbubbles. The work may significantly impact a wide range of processes, including operations in the pulp and paper industry; ultrapure water production for the semiconductor, pharmaceutical, and other industries; municipal potable water production; and wastewater treatment.

\subsubsection{Progress}

A corona-discharge ozone-generator system, with oxygen as the feed stream, is being used in these experiments. The exit stream is accumulated in a storage tank from which a sample is drawn by a syringe to be introduced in the ozonation reactor through a syringe pump. An electrostaticspraying system is used to spray the ozone-oxygen mixture in the form of microbubbles into a batch 
ozonation reactor. Ozone concentration is monitored either by UV (gas phase) or by colorimetry (liquid phase). The oxidation rate of phenol in the ozonation reactor is monitored.

Preliminary results of phenol oxidation by ozone showed a higher reaction rate for microbubble injection than that observed with a bubble diffuser system, which is a competitive method of producing small bubbles of ozone in water. Systematic experiments have also demonstrated enhanced ozone transport rates from the gas phase to the aqueous phase as compared with bubble diffuser systems.

\subsection{DEVELOPMENT PROGRAM IN ELECTRODISTILLATION (C. Tsouris, D. W. DePaoli, and K. D. Blankenship) \\ Contact: C. Tsouris \\ Telephone: (423) 241-3246 \\ Internet: tq9@ornl.gov}

Summary: The enhancement of distillation efficiency by using electric fields is investigated in this task. A three-stage distillation column has been designed and constructed, which allows high-intensity electric fields to be formed between the three discs. Experiments are conducted to determine whether electric fields can enhance the separation efficiency of binary mixtures.

\subsubsection{Purpose and Scope}

The primary objective of this project is to enhance the separation factor of distillation of liquid mixtures by using electric fields. It is expected that transport effects on pumping, spraying, and mixing of bubbles in the liquid, as well as equilibria effects, will enhance the separation. These expectations are supported by earlier work on phase equilibria modification by electric fields, batchdistillation experiments, and EHD experiments using gas-liquid systems. The work may significantly impact industrial separations by distillation, which consume 2.4 quadrillion British thermal units per year in the United States alone.

\subsubsection{Progress}

A distillation column consisting of special arrangements of glassware and metal plates has been designed. The column has a boiling flask, four compartments (each $10 \mathrm{~cm}$ in length), a condenser, and metal plates separating the compartments. Distillation experiments have been conducted using isopropanol-water mixtures under high-intensity electric fields. Initial results showed an effect of the electric field on the separation factor of the two mixtures. To maximize this 
effect, the geometry of the electrodes has been modified so that the electric current through the system is minimized. Experiments with the modified electrodes are currently in progress.

\subsection{PARTICLE INTERACTIONS (C. Tsouris, S. Yiacoumi, and K. Subramaniam)}

Contact: C. Tsouris

Telephone: (423) 241-3246

Internet: tq9@ornl.gov

Summary: In this task, we investigate the interactions of particles in reactive systems and under the influence of magnetic fields. Sorption of metal ions by colloidal particles changes the surface properties of the particles, as well as the chemical speciation of the sorbing species. It has been found that metal ion uptake can play a significant role in particle flocculation kinetics. Aggregation and filtration of magnetic particles under the influence of magnetic fields are also investigated.

\subsubsection{Purpose and Scope}

The geochemical fate of metal ions is controlled by their reactions with surfaces at the solidwater interface. Most colloidal phases in aqueous solutions are effective sorbents of such contaminants. As metal ions are sorbed on the surface of colloidal particles, the surface properties of the particles change. These changes may cause stable particles to become unstable with respect to coagulation. The purpose of this work is to determine the conditions under which sorption of metal ions destabilizes the colloidal particles. A unified modeling approach of metal ion sorption and coagulation of colloidal particles is expected to be developed in this work. The enhancement of coagulation, sedimentation, and filtration rates of magnetic particles under magnetic fields is also investigated in this program, with the objective to increase the separation efficiency of particles and other contaminants from fluids.

\subsubsection{Progress}

Sorption of copper and cadmium ions by ferric oxide particles has been studied using batch equilibrium and kinetics experiments. The sorption process is $\mathrm{pH}$ dependent, with the uptake increasing at high $\mathrm{pH}$ values. An increase in the equilibrium $\mathrm{pH}$ is observed when the initial $\mathrm{pH}$ is in the acidic range, and a decrease from initial values is observed in the basic range, in both copper and cadmium sorption. A large increase in the zeta potential of the particles is also observed during sorption. This increase occurs as a result of surface charge neutralization due to metal ion uptake. Particle destabilization occurs as a result of metal ion sorption. Kinetics experiments indicate that the uptake of copper by ferric oxide particles is a slow process. Changes in the size distribution of 
the aggregates of ferric oxide particles during uptake of ions are observed in the sorption kinetics studies. These results are discussed in a paper that has been submitted for publication. Experiments are currently conducted using silica particles with copper ions in aqueous solutions.

Particle coagulation studies in shear-flow and high-gradient magnetic-filtration experiments and modeling were continued. The results have been summarized into two papers focused on highgradient magnetic-filtration modeling and experimental results. A two-dimensional particle dynamics simulation has been developed to study the fractal dimension of aggregates under reactionand diffusion-limited regimes. Results showed that one-dimensional chains are formed when magnetic particles coagulate under a magnetic field. These chains are oriented with the field lines. It has also been found that when the magnetic force is comparable with electrostatic and van der Waals forces, two dimensional aggregates are formed, which are still aligned with the field lines. On the basis of these simulation results, experiments have been scheduled for the next quarter, with the objective of studying the effect of interparticle forces on chain formation.

\subsection{INDUSTRIAL INTERACTION (D. W. DePaoli)}

Contact: D. W. DePaoli

Telephone: (423) 574-6817

Internet: ddi@ornl.gov

Summary: D. W. DePaoli was one of four ORNL employees who spent 3 weeks in an offsite assignment at the R\&D centers of a major industrial firm. Efforts have continued to develop contacts and to host visitors from the company. Several potential collaborative efforts have been identified.

\subsubsection{Purpose and Scope}

PPG Industries and ORNL have been working to develop opportunities for technology transfer and collaborative research. PPG has four major business units-glass, fiberglass, coatings and resins, and specialty chemicals. Four ORNL staff members were assigned to cover these business units in the technical areas of chemistry, analytical chemistry, metallurgy, and instrumentation and controls. These staff members continue to serve as points of contact to develop links between ORNL capabilities and PPG's needs.

\subsubsection{Results}

During this quarter, each of the ORNL contacts made a presentation to ORNL staff on potential areas of opportunity for interaction with PPG. Two sets of PPG personnel visited with 
CTD researchers who were identified as working on topics pertinent to the guests's needs. In addition, a statement of work authored by X. Zhang and D. W. DePaoli for a potential cooperative research and development agreement was submitted to PPG in October. Communications with PPG contacts are continuing.

\subsection{PUBLICATIONS}

M. Z.-C. Hu, J. T. Zielke, J.-S. Lin, and C. H. Byers, "Small-Angle X-Ray Scattering Studies of Early-Stage Colloids Formation by Thermohydrolytic Polymerization of Aqueous Zirconyl Salt Solutions," accepted for publication in Journal of Materials Research, 1998.

A. Singhal, M. T. Harris, L. M. Toth, M. Z.-C. Hu, G. Beaucage, K. D. Keefer, J.-S. Lin, and J. R. Peterson, "Study of Growth Kinetics and Structure of Zirconium Hydrous Polymers in an Alkoxide System," submitted to Journal of Non-Crystalline Solids, 1997.

M. A. Norato, C. Tsouris, and L. L. Tavlarides, "Phase Inversion Studies in Liquid-Liquid Dispersions," submitted for publication in Canadian Journal of Chemical Engineering, October 1997.

C. Tsouris, W.-T. Shin, and S. Yiacoumi, "Spraying, Pumping, and Mixing of Fluids by Electric Fields," submitted for publication in Canadian Journal of Chemical Engineers, October 1997.

T.-Y. Ying, C. J. Chin, S.-C. Lu, S. Yiacoumi, M. R. Chattin, M. A. Spurrier, D. W. DePaoli, and C. Tsouris, "Magnetic-Seeding Filtration," submitted for publication in Separation Science and Technology, October 1997.

K. Subramaniam, S. Yiacoumi, and C. Tsouris., "Effect of Sorption on Particle Flocculation Kinetics: Experimental Studies," submitted for publication in Separation Science and Technology, October 1997.

K. D. Blankenship, V. M. Shah, and C. Tsouris, "Distillation Under Electric Fields," submitted for publication in Separation Science and Technology, October 1997.

T.-Y. Ying, S. Yiacoumi, and C. Tsouris, "High-Gradient Magnetically Seeded Filtration," submitted for publication in Chemical Engineering Science, December 1997. 


\section{FLUID STRUCTURE AND PROPERTIES}

\section{H. D. Cochran}

\subsection{INTERACTIONS OF SOLUTES, SOLVENTS, AND SURFACES (H. D. Cochran, H.-C. Li, and K. D. Heath) \\ Contact: H. D. Cochran \\ Telephone: (423) 574-6821 \\ Internet: hdc@ornl.gov}

Summary: Molecular-based studies of solutions in supercritical fluids include X-ray and neutron-scattering experiments, molecular simulations, and integral equation theory to pursue fundamental understanding of how supercritical solutions behave in practical separations processes.

\subsubsection{Objective}

This program focuses on our fundamental interest in understanding the practical behavior of separation processes in terms of the underlying molecular interactions. It addresses two areas where previously available theory has proven inadequate: (1) supercritical solutions are characterized by interactions between molecules that are extremely disparate in size and attractive energy and (2) the dynamics of adsorption is dominated by the effect of extreme nonhomogeneity.

\subsubsection{Progress}

Studies by K. D. Heath of electrodispersion of water into supercritical carbon dioxide have continued. Successful results have been described in a Report of Possible Subject Invention. The apparatus has been modified to incorporate the most successful approaches and to make operation more routine and stable. Experiments are in progress to demonstrate the efficient extraction of high-purity ethanol from 12 vol \% ethanol-water solution into supercritical carbon dioxide.

Planned small-angle neutron-scattering (SANS) experiments have been delayed by the unscheduled shutdown of the High Flux Isotope Reactor followed by the extended shutdown for in-service inspection. We hope there will be one or two operating periods next quarter before the planned one-year-plus shutdown of the SANS facility.

H.-C. Li has successfully reduced the number of constants in the generalized quartic equation of state by $40 \%$ without loss of accuracy and will begin testing the simplified equation with binary and temary mixtures next quarter. 
4.2 MOLECULAR-BASED STUDY OF REVERSE MICELLES IN SUPERCRITICAL $\mathrm{CO}_{2}$ (P. T. Cummings, H. D. Cochran, G. D. Wignall, J. M. DeSimone, E. J. Beckman, J. D. Londono, S.-T. Cui, S. Salaniwal, and K. D. Heath)

Contact: H. D. Cochran

Telephone : (423) 574-6821

Internet: hdc@ornl.gov

Summary: This multi-institutional project aims to develop a molecular understanding of reverse micelles in supercritical carbon dioxide through small-angle scattering experiments and molecular simulation calculations and, in particular, to determine what molecular characteristics lead to successful surfactants for this application.

\subsubsection{Objective}

The aim of this multi-institutional project is to develop a molecular understanding of reverse micelles in supercritical carbon dioxide through small-angle scattering experiments and molecular simulation calculations and, in particular, to determine what molecular characteristics lead to successful surfactants for this application.

\subsubsection{Progress}

Our paper, "The Morphology of Blockcopolymer Micelles in Supercritical Carbon Dioxide by Small Angle Neutron and X-ray Scattering," has been published in the Journal of Applied Crystallography. J. D. Londono accepted a position with DuPont during the quarter, and applicants to replace him are undergoing screening.

S. Salaniwal has initiated molecular dynamics simulations of systems of linear alkane molecules in supercritical carbon dioxide and similar simulations of systems of linear perfluoroalkane molecules in supercritical carbon dioxide. S.-T. Cui is also initiating vapor-liquid phase equilibrium calculations by the Gibbs ensemble Monte Carlo technique of the perfluoroalkane systems in supercritical carbon dioxide for comparison with published results. This comparison will test our intermolecular potential model for perfluoroalkanes in mixtures with carbon dioxide. These simple systems are constituents of more complex surfactant systems to be studied later.

4.3 STRUCTURE AND PROPERTIES OF CHAIN MOLECULE SYSTEMS UNDER SHEAR (H. D. Cochran, P. T. Cummings, S.-T. Cui, J. D. Moore, Yu. V. Kalyuzhyi, and M. D. Dadmun)

Contact: H. D. Cochran

Telephone: (423)574-6821

Internet: hdc@ornl.gov 
Summary: This program employs experiments, molecular simulations, and theory to understand the structure and properties of systems of long-chain molecules under homogeneous shear (planar Couette flow).

\subsubsection{Objective}

The aim of this program is to develop techniques for quantitative, molecular-based prediction of the structure and properties of systems of long-chain molecules undergoing shear flow through coarse graining of accurate, atomistic simulations of shorter-chain systems, as well as coarse graining based on theory and verified by careful small-angle light-scattering, SAXS, and SANS experiments on sheared systems.

\subsubsection{Progress}

Yu. V. Kalyuzhnyi has written and debugged a code to solve the nonequilibrium Ornstein-Zernike equation in the Percus-Yevick approximation for systems of simple fluids. In this theory the shear field is represented as an anisotropic potential. S.-T. Cui will initiate nonequilibrium molecular dynamics (NEMD) simulations of the same system to test the theory. Initial calculations are at low strain rate in the Newtonian regime for which the angular pair correlation function from theory and simulation will be compared. If the theory appears promising, extension to the non-Newtonian regime is straightforward.

J. D. Moore has begun molecular dynamics simulations, using an accurate intermolecular potential model, of a system of linear alkane chains 100 carbons long. The relaxation time for this system appears to be about 1.2 million timesteps. After equilibration and measurement of some equilibrium properties, NEMD calculations will explore the behavior of these long-chain molecules under shear. The longest-chain molecule previously studied under shear with an accurate potential model was 30 carbons long. Studies of different isomers of 30-carbon alkanes are continuing.

Candidates have been screened for the postdoctoral scholar position to develop and use the ultrahigh-strain-rate shear cell for scattering experiments, and the most promising candidate has been invited for an interview.

\subsection{PUBLICATIONS}

J. D. Moore, S. T. Cui, H. D. Cochran, and P. T. Cummings, "Lubricant Characterization by Molecular Simulation," AIChE J. 43, 3260-63 (1997).

S. A. Gupta, H. D. Cochran, and P. T. Cummings, "Shear Behavior of Squalane and Tetracosane Under Extreme Confinement. I. Model, Simulation Method, and Interfacial Slip," J. Chem. Phys. 107, 10316-26 (1997). 
S. A. Gupta, H. D. Cochran, and P. T. Cummings, "Shear Behavior of Squalane and Tetracosane Under Extreme Confinement. II. Confined Film Structure," J. Chem. Phys. 107, 10327-34 (1997).

S. A. Gupta, H. D. Cochran, and P. T. Cummings, "Shear Behavior of Squalane and Tetracosane Under Extreme Confinement. III. Effect of Confinement on Viscosity," J. Chem. Phys. 107, 10335-43 (1997).

J. D. Londono, R. Dharmapurikar, H. D. Cochran, G. D. Wignall, J. B. McClain, J. R. Combes, D. E. Betts, D. A. Canelas, J. M. DeSimone, E. T. Samulski, D. Chillura-Martino, and R. Triolo, "The Morphology of Blockcopolymer Micelles in Supercritical Carbon Dioxide by Small Angle Neutron and X-ray Scattering," J. Appl. Crystallog. 30, 690-95 (1997).

S. T. Cui, P. T. Cummings, and H. D. Cochran, "Configurational Bias Gibbs Ensemble Monte Carlo Simulation of Vapor-Liquid Equilibria of Linear and Short-Branched Alkanes," Fluid Phase Equilib. 141, 45-61 (1997).

\section{BIOTECHNOLOGY RESEARCH}

\section{E. Greenbaum}

\subsection{KINETICS OF ENZYME-CATALYZED REACTIONS (E. Greenbaum, J. Woodward,} J. W. Lee, C. V. Tevault, and S. L. Blankinship)

Contact: E. Greenbaum

Telephone: (423) 574-6835

Internet: exg@ornl.gov

Summary: An extensive study of transition-metal compounds resulted in the identification of four new Hill reagents, each of which can be photosynthetically reduced to form a metallic catalyst at the reducing site of photosystem I (PSI) in the thylakoid membrane. The kinetics of a novel thermophilic cellulase were also investigated.

\subsubsection{Purpose and Scope}

This research program is a study of the fundamental reactions of photosynthesis and conversion of light energy into chemical energy. Sustained simultaneous photoevolution of molecular hydrogen and oxygen is studied as a model photosynthetic reaction in which the energyrich product produced is molecular hydrogen, rather than a carbon dioxide fixation compound. Basic questions such as the molecular mechanisms of gas evolution, thermodynamic limits of photosynthesis, and minimum number of light reactions that required to split water to hydrogen and oxygen are studied. Fundamental studies on the enzymology of cellulase are also performed. 


\subsubsection{Progress}

We report the results of an extensive experimental survey and characterization of over 20 species of transition-metal compounds for their activity in the Hill reaction and photoprecipitation of metal at the lipid-water interface of photosynthetic thylakoid membranes. Four new Hill reagents were identified: $\mathrm{PtCl}_{4}, \mathrm{OsCl}_{3},\left[\mathrm{RuCl}_{6}\right]^{2-}$, and $\left[\mathrm{RuCl}_{6}\right]^{3-}$. Each can be photosynthetically reduced to form a metallic catalyst at the reducing site of PSI in the thylakoid membranes. Negative charge of the metal compound species is apparently essential for their interaction with the reducing site of PSI. When $\mathrm{PtCl}_{4}$ and $\mathrm{OsCl}_{3}$ are dissolved in water, they combine with water molecules to form $\mathrm{H}_{2} \mathrm{PtCl}_{4}(\mathrm{OH})_{2}$ and $\mathrm{H}_{3} \mathrm{OsCl}_{3}(\mathrm{OH})_{3}$, which can dissociate to negatively charged species $\left[\mathrm{PtCl}_{4}(\mathrm{OH})_{2}\right]^{2-}$ and $\left[\mathrm{OsCl}_{3}(\mathrm{OH})_{3}\right]^{3-}$ at neutral $\mathrm{pH}$. Metallic ruthenium can also catalyze reduction of protons for $\mathrm{H}_{2}$ production, in addition to its known catalytic ability to fix $\mathrm{CO}_{2}$. These findings could have important implications for nanofabrication and biometallocatalysis to harness the power of photosynthetic systems.

We have studied the kinetics of a thermophilic cellulase from Thermotoga maritima. The main findings are summarized as follows. It has the highest activity on barley $\beta$-glucan, compared with other cellulases $\left(80^{\circ} \mathrm{C}\right.$, optimal temperature; optimal $\left.\mathrm{pH}, 5.0\right)$. It is stable for at least $4 \mathrm{~h}$ at $80^{\circ} \mathrm{C}$. The main product of its reaction on Avicel is cellobiose. However, in order to determine whether the enzyme is an exogluconase or endoglucanase, we conducted the following experiments. First, we measured the rate of carboxymethylcellulose (CMC) and barley B-glucan hydrolysis by T. maritima cellulase compared with the rates of EG II, a known endogluconase, and CBH I, a known exogluconase from the mesophilic fungus Trichoderma reesei using viscosity-reduction measurements. Whereas $\mathrm{CBH}$ I had little effect on the viscosity of $\mathrm{CMC}$ or $\beta$-glucan, EG II and T. maritima cellulase possessed the ability to reduce the viscosity of these substrates similarly. It was concluded that the T. maritima cellulase is an endoglucanase. It is a novel enzyme in that it has only $38 \%$ identity with sequences of known cellulases and does not possess an inherent cellulosebinding domain. It possesses a high degree of synergy with $\mathrm{CBH}$ I.

\subsection{BIOMOLECULAR ELECTRONICS (E. Greenbaum, J. W. Lee, and I. Lee)}

Contact: E. Greenbaum

Telephone: (423) 574-6835

Internet: exg@ornl.gov

Summary: During the period, Kelvin probe force microscopy was used to measure the charge separation in a single PSI reaction center under laser illumination. Further experimentation is planned. 


\subsubsection{Purpose and Scope}

This research project is focused on the development of molecular optoelectronic devices. It is motivated by knowledge of the intrinsic photophysical properties of the reaction centers of photosynthesis: nanometer dimensions, picosecond response times, and the ability to generate potential differences of about $1 \mathrm{~V}$ upon absorption of a photon. The research is based on original discoveries in molecular electronics made in the ORNL Chemical Technology Division. These include (1) first demonstration of direct electrical contact with the electron transport chain of photosynthesis, (2) photoflash deposition of metallic platinum at the site of electron emergence from the PSI reaction center of photosynthesis, (3) establishment of a novel platinization "welding" technique that allows construction of two-dimensional arrays of PSI reaction centers on a metal surface, and (4) first demonstration of a biomolecular diode in a single isolated photosynthetic reaction center. Taken together, these results indicate that purified reaction centers of photosynthesis are very promising structures for the development of the next generation of optoelectronic devices.

\subsubsection{Progress}

During this report period we have performed experiments to measure the charge separation in a single PSI reaction center under laser illumination. We used a Kelvin probe force microscope, which can measure both the surface potential and the topographic image simultaneously, without contacting the sample surface. The resulting photoinduced changes in dipole moments of the highly oriented PSI reaction centers were detected as the surface potential changes on the gold substrate. Further experiments are planned to improved the resolution and signal-to-noise level. A switchable external light source is also under construction to provide a dark background reference signal.

\subsection{RENEWABLE HYDROGEN PRODUCTION (E. Greenbaum, J. W. Lee, C. V. Tevault, and S. L. Blankinship)}

Contact: E. Greenbaum

Telephone: (423) 574-6835

Internet: exg@ornl.gov

Summary: Infrared spectroscopy was used to measure the absolute yields of $\mathrm{CO}_{2}$ uptake per mole of chlorophyll per flash of light as a function of frequency. 


\subsubsection{Purpose and Scope}

The purpose of this research program is the production of renewable hydrogen by photosynthetic water splitting. Experiments on the production of hydrogen and oxygen with a view towards the design and development of a real-world process system are being performed. The limitations of the photosynthetic process, the light saturation curves, and the long-term stability and endurance of microalgae are under investigation.

\subsubsection{Progress}

Measurements of the absolute yields of $\mathrm{CO}_{2}$ uptake per mole of chlorophyll per singleturnover saturating flash of light $\left(1.2 \mu\right.$ s full width at half maximum, $\left.2.44 \times 10^{-4} \mu \mathrm{E} \cdot \mathrm{cm}^{-2} \cdot \mathrm{flash}^{-1}\right)$ as a function of frequency in the range $0.04-10 \mathrm{~Hz}$ have been performed on wild-type Chlorella vulgaris. Using $\mathrm{CO}_{2}$ infrared spectroscopy as the measuring tool with a continuous-flow air carrier stream, these measurements extend, in the low-frequency region, the seminal experiments of Emerson and Arnold, which, because of limitations of the Barcroft-Warburg manometric technique, used $0.5 \mathrm{~Hz}$ as the lower frequency limit. At $20^{\circ} \mathrm{C}$, an approximate doubling of the yield per flash below $1 \mathrm{~Hz}$, peaking at about $0.1 \mathrm{~Hz}$, is observed. Whereas the flash yield in the $1-$ to $10-\mathrm{Hz}$ range is correctly described by the Z-scheme pathway, in which PSI generates reductant for $\mathrm{CO}_{2}$ fixation, the absolute flash yield below $1 \mathrm{~Hz}$ is not consistent with this model. It is, however, consistent with a model in which photosystem II (PSII) can generate reductant for $\mathrm{CO}_{2}$ fixation and with the wellknown fact that the PSII:PSI ratio is $>1$ for eukaryotic algae.

\subsection{ENZYMES FROM EXTREMOPHILES IN BIOPROCESSING AND BIOREME- DIATION (J. Woodward and B. R. Evans)}

Contact: J. Woodward

Telephone: (423) 574-6826

Internet: oop@ornl.gov

Summary: Isolation of ORNL thermophilic microorganisms was carried out. Three isolates from a subsurface mixed culture were grown on xylan, revealing cellulase and xylanase activity on the supernatants.

Isolation of ORNL thermophilic microorganisms was carried out by Ji-Zhong Zhou and Heshu Huang of the ORNL Environmental Sciences Division. A mixed culture had been obtained from a $2.7-\mathrm{km}$ drill hole as described previously. The mixed culture had been found to produce both xylanase and cellulase activities when grown on xylan. In order to isolate the cellulolytic thermophiles, the mixed culture was streaked on xylan plates. Single colonies that grew on the plates were 
used to innoculate $150 \mathrm{~mL}$ of media containing xylan as the carbon source. The cultures were grown at $65^{\circ} \mathrm{C}$ for $2 \mathrm{~d}$ and then centrifuged. Cell pellets and supernatants were stored at $-70^{\circ} \mathrm{C}$. The culture supernatants were thawed and assayed for activity on birchwood xylan and microcrystalline cellulose at $70^{\circ} \mathrm{C}$ in $50 \mathrm{mM}$ potassium phosphate, $\mathrm{pH} 6.0$.

The culture supernatants were dialyzed at $4^{\circ} \mathrm{C}$ for $18 \mathrm{~h}$ against $50 \mathrm{mM}$ Tris- $\mathrm{HCl}, \mathrm{pH} 7.0$. The dialzyed supernatants were then applied to 1.5 - by $8.0-\mathrm{cm}$ columns of Pharmacia DEAE Sepharose equilibrated in $50 \mathrm{~m} M$ Tris- $\mathrm{HCl}, \mathrm{pH} 7.0$. Protein fractions were eluted with $50 \mathrm{~m} M$ Tris$\mathrm{HCl}, 1.0 \mathrm{M} \mathrm{NaCl}, \mathrm{pH}$ 7.0. The eluted protein was assayed for cellulase and xylanase activity.

Examination of the proteins eluted from the DEAE chromatography on sodium dodecyl sulfate and isoelectric focussing polyacrylamide gels indicated that at least six proteins were present in the peaks eluted with $1.0 \mathrm{M} \mathrm{NaCl}$. Gel filtration was used to separate the components. Concentrated protein from the X-1 supernatant that had been eluted from the DEAE column with $1 \mathrm{M} \mathrm{NaCl}$ ( $1 \mathrm{~mL}, 0.233 \mathrm{mg} / \mathrm{mL}$ ) was loaded on a Pharmacia 10/30 Superdex-75 column equilibrated in $20 \mathrm{mM}$ Tris- $\mathrm{HCl}, \mathrm{pH} 8.0$. Fractions $(1 \mathrm{~mL})$ were eluted and assayed for protein concentration and activity on birchwood xylan, Avicel, and CMC. Activity assays were carried out by following reducing sugar production at $70^{\circ} \mathrm{C}$ in $50 \mathrm{mM}$ potassium phosphate buffer, $\mathrm{pH} 6.0$, with $1 \%$ substrate. The brown color eluted in fractions 13-19, necessitating the use of the Coomassie blue protein assay to determine the protein concentration of the fractions. Superdex-75 has a fractionation range of $70,000-3000 \mathrm{~g} / \mathrm{mol}$ for globular proteins.

Three isolates from a thermophilic, subsurface mixed culture were grown on xylan. The culture supernatants were found to contain cellulase and xylanase activity. The cellulase and xylanase activities were found to bind to DEAE Sepharose at $\mathrm{pH} 7.0$. Isoelectric focusing gels and fractionation by molecular weight were used to analyze the composition of the supernatant of one of the isolates, $X-1$. The enzymes appear to be acidic and to vary in size from 70,000 to $20,000 \mathrm{~g} / \mathrm{mol}$. Variation of the relative activities on xylan, Avicel, and CMC between the Superdex-75 pools indicates that a typical array of exoglucanases, endoglucanases, and xylanases is probably present. The lower specific activity on Avicel after Superdex-75 fractionation may indicate that there is synergy between the enzyme components that are separated by this chromatography. 


\subsection{ENZYMATIC CONVERSION OF BIOMASS TO HYDROGEN (J. Woodward and B. R. Evans)}

Contact: J. Woodward

Telephone: (423) 574-6826

Internet: oop@ornl.gov

Summary: Research continued to focus on improving the molar yields of hydrogen from glucose. Experimentation was also initiated to convert environmental sources of sugar (biomass) to hydrogen.

During this reporting period the research emphasis has been on improving the molar yields of hydrogen from glucose, utilizing enzymes of the pentose phosphate pathway. It has also been determined that for long-term experiments on hydrogen production, it is necessary to incorporate microbial growth inhibitors into the reaction vessel. Initiation of experiments on the conversion of biomass (environmental sources of sugar) to hydrogen has also commenced. Progress includes the development of a method for the extraction of maple tree sap from tree branches and the setup and operation of a high-performance liquid chromatograph for the determination of the type and concentration of sugar in sap. It was determined that the major sugar in maple tree sap is sucrose. Utilizing the enzymes invertase, glucose isomerase, glucose dehydrogenase, and hydrogenase, it has been established that sucrose can be enzymatically hydrolyzed to glucose and fructose (the latter being isomerized to glucose) and hydrogen generated by the oxidation of glucose. Depending on the sucrose concentration, a range of power output of $0.3-1.18 \mathrm{~mW}$ was obtained. Some of the problems still to be overcome include improving the rate at which fructose is isomerized to glucose and stabilization of glucose dehydrogenase. A major research proposal to the Defense Advanced Research Projects Agency is being prepared for submission in December. If successful, this will allow continuation of this work in collaboration with U.S. industry that specializes in biofuel cell production.

\subsection{DEVELOPMENT OF MICROCYCLE TECHNOLOGY FOR THE LARGE-SCALE PRODUCTION OF FUNGAL ENZYMES (B. D. Faison)}

Contact: B. D. Faison

Telephone: (423) 574-8292

Internet: fqd@ornl.gov

Summary: During the current reporting period, preparations were made to cultivate test fungi under a microcycle regime. A key piece of laboratory equipment-an inverted-light (phasecontrast) microscope capable of direct observation and photomicrography of differentiating fungal cells-was obtained and installed. The principal investigator has become familiar with and has 
carried out minimal troubleshooting of the system, including verifying its ability to record vegetative, conidial, and microcycle growth.

\subsubsection{Purpose and Scope}

Most $(\sim 55 \%)$ of the enzymes produced by or for U.S. industry are of fungal origin. However, methods for the efficient production of fungal enzymes are lacking. "Efficient" enzyme production would allow maximal enzyme yield from minimal biomass, decrease nutrient supply requirements, and facilitate product recovery. For spore-borne enzymes, efficiency may require the use of microcycle technology (forcing fungi to cycle rapidly between growth and sporulation). Microcycles may be achieved via manipulation of nutrient titers and/or quality, temperature, or irradiation or via addition of specific physiological substrates (e.g., enzyme inducers). This approach has not yet been used for fungal enzyme production. This high-risk experimental work is being conducted with support from the ORNL Seed Money Program.

\subsubsection{Progress}

This project was initiated in July 1997. Certified cultures of the test organisms-Aspergillus niger, Phanerochaete chrysosporium, and Trichoderma reesei-were purchased and successfully propagated. Additional laboratory space within Building $4500 \mathrm{~N}$ is being prepared and customized for this work.

The multiple delays associated with this project to date have led to direct manipulation of $P$. chrysosporium (including its type strain, ME-446; its industrial strain, VKM-1761; and a hyperproducing mutant, SC-26) to determine its amenability to the microcycle regime and subsequent lignin peroxidase production. A. niger and $T$. reesei, which produce protease and cellulase, respectively, will be investigated only as time permits.

\subsection{PUBLICATIONS}

I. Lee, J. W. Lee, and E. Greenbaum, "Biomolecular Electronics: Vectorial Arrays of Photosynthetic Reaction Centers," Phys. Rev. Lett. 79, 3294-97 (1997).

E. Greenbaum, J. W. Lee, S. L. Blankinship, and C. V. Tevault, "Hydrogen and Oxygen Production in Mutant Fud26 of Chlamydomonas reinhardtii," in Proceedings of the 1997 U.S. DOE Hydrogen Program Review, NREL/CP-340-23722, May 21-23, 1997, Herndon, Virginia.

J. W. Lee, R. T. Collins, and E. Greenbaum, "Molecular Ionic Probes: A New Class of Hill Reagents and Their Potential for Nanofabrication and Biometallocatalysis," J. Phys. Chem. B in press. 
N. Hershlag, I. Hurley, and J. Woodward, "A Simple Method to Demonstrate the Enzymatic Production of Hydrogen from Sugar," accepted for publication in the Journal of Chemical Education.

E. Greenbaum and J. W. Lee, "Photosynthetic Hydrogen and Oxygen Production by Green Algae," Proceedings of the International Conference on Biological Hydrogen Production, BioHydrogen '97, Waikoloa, Hawaii, June 23-26, 1997, in press.

S.V. Liu, J. Zhou, C. Zhang, D. R. Cole, and M. Gajdarziska-Josifovksa, "Thermophilic Fe(III)Reducing Bacteria from the Deep Subsurface: The Evolutionary Implications," Science 277, 1106-09 (1997).

\subsection{PRESENTATIONS}

E. Greenbaum, "New Photosynthetic Pathways: Renewable Fuels Production and Biomolecular Electronics," research seminar presented at the Marine Biotechnology Institute, Kamaishi, Japan, December 9, 1997.

E. Greenbaum, "New Photosynthetic Pathways: Renewable Fuels Production and Biomolecular Electronics," research seminar presented at the Research Institute for Innovative Technology for the Earth, Tokyo, Japan, December 11, 1997.

E. Greenbaum, "New Photosynthetic Pathways: Renewable Fuels Production and Biomolecular Electronics," research seminar presented at Tokyo University of Agriculture and Technology, Tokyo, Japan, December 12, 1997.

E. Greenbaum, "New Photosynthetic Pathways: Renewable Fuels Production and Biomolecular Electronics," research seminar presented at the Tokyo Institute of Technology, Tokyo, Japan, December 15, 1997.

E. Greenbaum, "New Photosynthetic Pathways: Renewable Fuels Production and Biomolecular Electronics," research seminar presented at the University of Tokyo, Tokyo, Japan, December 16, 1997.

E. Greenbaum, "New Photosynthetic Pathways: Renewable Fuels Production and Biomolecular Electronics," research seminar presented at the National Institute for Advanced Interdisciplinary Research, Tsukuba, Japan, December 16, 1997. 


\title{
6. MOLECULAR STUDIES
}

\section{P. T. Cummings}

\subsection{AQUEOUS ELECTROLYTE SOLUTIONS AT AMBIENT AND SUPERCRITICAL CONDITIONS (P. T. Cummings, A. A. Chialvo, S. H. Lee, and T. Driesner)}

\author{
Contact: P. T. Cummings \\ Telephone: (423) 2414779 \\ Internet: u53@ornl.gov
}

Summary: Development of a simulation code for water with a flexible potential was initiated. Preparation of a major invited review article on water and supercritical solutions was initiated. Simulations of limiting conductance in supercritical aqueous electrolyte solutions were begun.

\subsubsection{Purpose and Scope}

This project is aimed at developing microscopic-level understanding of aqueous electrolyte solutions using a combination of molecular simulation, statistical mechanical theory and experimental measurement of VLE and solution densities. The state conditions of interest range from ambient conditions to high-temperature/high-pressure supercritical conditions (such as those encountered in power plant steam cycles and supercritical water oxidation).

\subsubsection{Progress}

Thomas Driesner initiated development of a molecular dynamics code for simulating water that employs the flexible $\mathrm{BJH}$ model of water. The goal of this work will be to simulate isotope effects in supercritical and ambient water, as well as make contact with measurements (extended $\mathrm{X}$-ray absorption fine structure) of the hydration shell of supercritical water around ions, and the spectroscopic properties of water.

Chialvo and Cummings were invited to write a review article on molecular simulation of supercritical water and aqueous solutions. During the current quarter, the literature was reviewed and many of the prominent researchers in the field contacted by letter to request reprints and preprints of their work.

Visiting Professor Song Hi Lee initiated molecular dynamics simulations of sodium and chlorine ions in supercritical water to calculate the limiting conductance as a function of density. The purpose of this study is to understand the change in slope of the limiting conductance with decreasing density. 


\subsection{THEORY AND MOLECULAR SIMULATION OF NONEQUILIBRIUMSYSTEMS (P. T. Cummings, A. Baranyai, S. T. Cui, J. D. Moore, and I. Borzsák)}

Contact: P. T. Cummings

Telephone: (423) 2414779

Internet: u53@ornl.gov

Summary: The viscosity and viscosity index of various linear and branched alkanes were in the process of being predicted computationally. A large-scale simulation of $\mathrm{C}_{100}$ was initiated.

\subsubsection{Purpose and Scope}

In this project, we study and develop new simulation algorithms for systems away from equilibrium. These algorithms form the basis for the calculation of transport properties using nonequilibrium molecular dynamics.

\subsubsection{Progress}

We continued production calculations on the Intel Paragons at ORNL of the viscosity of various linear and branched alkanes and in particular focused on the viscosity index of another branched C30 alkane to complement our earlier work on squalane (also a branched C30 alkane, for which excellent agreement with experiment was found).

During the quarter, we initiated a simulation of liquid $\mathrm{C}_{100}$ using the massively parallel Cray T3E supercomputer located at the National Energy Research Supercomputing Center in Lawrence Berkeley National Laboratory, as well as Cray T3Es located at Cray headquarters in Minnesota. The goal of the $\mathrm{C}_{100}$ simulation will be to test the current limits of feasible calculation of equilibrium and transport properties. It will also provide a set of data that can be used for coarse-graining studies at a future date.

\subsection{INTEGRAL EQUATION THEORIES OF MOLECULAR FLUIDS (P. T. Cummings, Yu. V. Kalyuzhnyi, and J. N. Herrera) \\ Contact: P. T. Cummings \\ Telephone: (423) 2414779 \\ Internet: u53@ornl.gov}

Summary: A statistical mechanical approach to model the structural properties of liquid metals was developed. 


\subsubsection{Purpose and Scope}

This project involves the use of integral equation methods to describe molecular fluids and polymers in the dense-liquid regime. The emphasis is on analytically solvable integral equation theories.

\subsubsection{Progress}

Noe Herrera, a faculty member from Mexico, joined the project in January 1997. He is partially supported by the Mexican equivalent of the National Science Foundation. Herrera and Cummings used integral equation theories to describe the structure of a wide range of liquid metals.

\subsection{MATHEMATICAL MODELING OF BACTERIAL MIGRATION THROUGH POROUS MEDIA WITH APPLICATION TO IN SITU BIOREMEDIATION (P. T. Cummings, R. M. Ford, K. C. Chen, ${ }^{*}$ and M. Jin*)}

Contact: P. T. Cummings

Telephone: (423) 2414779

Internet: u53@ornl.gov

Summary: Refinement of an efficient code for studying in situ bioremediation processes at the macroscopic and field-scale level was continued.

\subsubsection{Purpose and Scope}

This project is part of a broad effort at the University of Virginia funded by the IBM Environmental Research Program with Roseanne Ford and Peter Cummings as coprincipal investigators. The goal of the project is to perform experimental studies and computer simulations of bacterial motion in bulk aqueous phases and in porous media to develop an understanding of the transport processes involved in in situ bioremediation and to subsequently develop mathematical models for these processes. The project funding ends December 31, 1997.

\subsubsection{Progress}

Progress was made on the development of two-dimensional finite-element codes for modeling in situ bioremediation processes at the macroscopic and field level. 


\subsection{FUNDAMENTAL CHEMISTRY AND THERMODYNAMICS OF HYDRO- THERMAL OXIDATION PROCESSES (J. M. Simonson, R. E. Mesmer, D. J. Wesolowksi, P. T. Cummings, and A. A. Chialvo)}

Contact: P. T. Cummings

Telephone: (423) 2414779

Internet: u53@ornl.gov

Summary: Progress was made on extending the Chialvo-Cummings molecular formalism for studying solvation and partial molar thermodynamic properties in supercritical fluid mixtures to reaction kinetics in supercritical fluid solvents.

\subsubsection{Purpose and Scope}

This 3-year project, supported by the new DOE Environmental Management Science Program, began September 1, 1996. The goal of the project is to use a combination of molecular theory/simulation and experimental measurements to develop a fundamental understanding of the thermophysical properties, phase equilibrium, and reaction processes involved in supercritical water oxidation (a new and promising technique for transforming hazardous organic waste).

\subsubsection{Progress}

During the current quarter, the Chialvo-Cummings molecular formalism for studying solvation and partial molar thermodynamic properties in supercritical fluid mixtures was extended to reaction kinetics in supercritical fluid solvents and used to provide an alternate explanation of recent experimental data published by Brenneke and Roberts. A paper detailing this work was submitted for publication.

\subsection{DEVELOPMENT AND APPLICATION OF FAST COMPUTATIONAL PROTEIN- FOLDING ALGORITHMS USING MASSIVELY PARALLEL SUPERCOMPUTERS (P. T. Cummings and P. H. LoCascio*)}

Contact: P. T. Cummings

Telephone: (423) 2414779

Internet: u53@ornl.gov

Summary: This project was initiated and resources recruited.

"Center for Computational Sciences, ORNL. 


\subsubsection{Purpose and Scope}

This 3-year project, supported by the Laboratory Director's Research and Development fund, began October 1, 1997. The goal of the project is to develop parallel implementations of the Geocore $a b$ initio exhaustive-search protein-folding algorithm and use the parallel version to predict the structures of larger proteins; to improve the performance of the Geocore algorithm; and to develop much faster, less exhaustive algorithms for very large proteins.

\subsubsection{Progress}

The focus during the current quarter has been setting up the personnel for the project. Phil LoCascio from the Center for Computational Sciences will perform parallelization of Geocore. A copy of the serial Geocore code was obtained from Dill's group at the University of California-San Francisco and preliminary assessments performed by profiling the code.

6.7 MOLECULAR-BASED STUDY OF REVERSED MICELLES INSUPERCRITICAL CARBON DIOXIDE FOR SOLVENT SUBSTITUTION IN THE U.S. CHEMICAL INDUSTRY (P. T. Cummings, H. D. Cochran, S. T. Cui, D. Londono, G. Wignall, A Habenschuss, E. Beckman, ${ }^{*}$ and J. M. DeSimone ${ }^{\dagger}$ )

Contact: H. D. Cochran and P. T. Cummings

Telephone: (423) 5746821 (HDC) and (423) 2414779 (PTC)

Internet: hdc@ornl.gov (HDC) and u53@ornl.gov (PTC)

Summary: See research description reported under H. D. Cochran.

\subsection{OTHER IMPORTANT ACTIVITIES}

Cummings chaired a workshop at the National Science Foundation entitled "Future Directions in Molecular Modeling and Simulation: Fundamentals and Applications," which was convened November 3-4, 1997. Over 40 experts from academia, industry, and government laboratories participated. A report is in preparation. More information is available at the web site http://flory.engr.utk.edu/nsf.

*University of Pittsburgh.

†University of North Carolina. 


\subsection{PUBLICATIONS}

\subsubsection{Submitted}

A. A. Chialvo, P. T. Cummings, J. J. Simonson, R. E. Mesmer, and H. D. Cochran, "The Importance of the Interplay Between Molecular Simulation and Neutron Scattering in Developing New Insights into the Structure of Water,"Ind. Eng. Res. (1997).

K. C. Chen, R. M. Ford, and P. T. Cummings, "Mathematical Models for Motile Bacterial Transport in Cylindrical Tubes," J. Theor. Biol. (1997).

M. Jin, R. M. Ford, and P. T. Cummings, "A New Numerical Method for Solving a Scalar Advection-Dispersion Equation with Sources," Water Resour. Res. (1997).

N. Herrera, P. T. Cummings, and H. Ru'z-Estrada, "Static Structure Factor for Simple Liquid Metals," Mol. Phys. (1997).

\subsubsection{Accepted}

P. T. Cummings and A. Baranyai, "Classical Dynamics of Nonequilibrium Processes in Fluids," to be published in the Encyclopedia of Computational Chemistry, edited by P. von Rague Schleyer, N. L. Allinger, T. Clark, J. Gasteiger, P. A. Kollman, and H. F. Schaefer III, John Wiley \& Sons.

A. A. Chialvo and P. T. Cummings, "Molecular Simulation of Supercritical Water and Aqueous Solutions," to be published in the Encyclopedia of Computational Chemistry, edited by P. von Rague Schleyer, N. L. Allinger, T. Clark, J. Gasteiger, P. A. Kollman, and H. F. Schaefer MI, John Wiley $\&$ Sons.

A. A. Chialvo and P. T. Cummings, "Simple Transferable Intermolecular Potential for the Molecular Simulation of Water over Wide Ranges of State Conditions," Fluid Phase Equilibria, accepted for publication (1997).

D. A. Kofke and P. T. Cummings, "Precision and Accuracy of Staged Free Energy Perturbation Methods for Computing the Chemical Potential by Molecular Simulation," Fluid Phase Equilibria, submitted for publication (1997).

D. A. Kofke, "Semigrand Canonical Monte Carlo Simulation: Integration Along Coexistence Lines," Adv. Chem. Phys., submitted for publication (1997).

S. H. Lee and P. T. Cummings, "Molecular Dynamics Simulation of the Rheology of N-decane and 4-Propyl-heptane," Mol. Simulation, in press. 


\subsubsection{Published}

A. A. Chialvo, P. T. Cummings, J. M. Simonson, and R. E. Mesmer, "Molecular Simulation Study of Ion Speciation in Supercritical Aqueous Solutions," J. Mol. Liq. 73/74 361-72 (1997).

J. D. Moore, S. T. Cui, P. T. Cummings, and H. D. Cochran, "Lubricant Characterization by Molecular Simulation," AIChE J. 43 3260-63 (1997).

D. A. Kofke and P. T. Cummings, "Quantitative Comparison and Optimization of Methods for Evaluating the Chemical Potential by Molecular Simulation," Mol. Phys. 92 973-96 (1997).

S. T. Cui, H. D. Cochran, and P. T. Cummings, "Configurational Bias Gibbs-Ensemble Monte Carlo Simulation of Vapor-Liquid Equilibria of Linear and Short-Branched Alkanes," Fluid Phase Equilibria 141 45-61 (1997).

S. A. Gupta, H. D. Cochran, and P. T. Cummings, "Shear Behavior of Squalane and Tetracosane Under Extreme Confinement. I. Model, Simulation Method, and Interfacial Slip," J. Chem. Phys. 107 10316-26 (1997).

S. A. Gupta, H. D. Cochran, and P. T. Cummings, "Shear Behavior of Squalane and Tetracosane Under Extreme Confinement. II. Confined Film Structure," J. Chem. Phys. 107 10327-34 (1997).

S. A. Gupta, H. D. Cochran, and P. T. Cummings, "Shear Behavior of Squalane and Tetracosane Under Extreme Confinement. III. Effect of Confinement on Viscosity," J. Chem. Phys. 107 10335-43 (1997).

I. Borzsak and P. T. Cummings, "Electrofreezing of Water in Molecular Dynamics Simulation Accelerated by Oscillatory Shear," Phys. Rev. E. 56 6279-82 (1997).

\subsection{PRESENTATIONS}

\subsubsection{Invited Seminars}

P. T. Cummings, "Molecular Simulation of Supercritical Water and of Ionic Association in Supercritical Aqueous Solutions," presented at the Chemical Technology Division, Oak Ridge National Laboratory, Oak Ridge, Tennessee, October 9, 1997.

P. T. Cummings, "Molecular Modeling and Simulation: Present and Future Tools for Physical Properties Prediction," presented at the Department of Chemical Engineering, Ohio State University, October 30, 1997.

\subsubsection{Invited Conferences}

P. T. Cummings, "Molecular Modeling and Simulation: Present and Future Tools for Physical Properties Prediction," presented at the CAST Division Plenary Session, American Institute of Chemical Engineers Annual Meeting, Los Angeles, California, November 16-21, 1997. 


\subsubsection{Contributed Conferences}

A. A. Chialvo and P. T. Cummings, "Static Electric Field Effect on the Residual and Excess Thermodynamic Properties of Aqueous Systems: A Coupling Parameter Approach by Molecular Simulation," presented at the American Institute of Chemical Engineers Annual Meeting, Los Angeles, California, November 16-21, 1997.

J. T. Slusher and P. T. Cummings, "Molecular Dynamics Simulation of Tetraalkyammonium Bromide/2-Propanol /Water Systems," presented at the American Institute of Chemical Engineers Annual Meeting, Los Angeles, California, November 16-21, 1997.

S. T. Cui, P. T. Cummings, and H. D. Cochran, "The Vapor-Liquid Phase Equilibria of Perfluoroalkanes from a New Potential Model," presented at the American Institute of Chemical Engineers Annual Meeting, Los Angeles, California, November 16-21, 1997.

S. T. Cui, S. A. Gupta, J. D. Moore, P. T. Cummings, and H. D. Cochran, "Molecular Simulation of Rheology and Phase Equilibria of Alkane Fluids," presented at the American Institute of Chemical Engineers Annual Meeting, Los Angeles, California, November 16-21, 1997.

S. A. Gupta, H. D. Cochran, and P. T. Cummings, "Rheology of Confined Liquid Alkanes by Nonequilibrium Molecular Dynamics," presented at the American Institute of Chemical Engineers Annual Meeting, Los Angeles, California, November 16-21, 1997.

D. A. Kofke and P. T. Cummings, "On the Computation of the Chemical Potential by Molecular Simulation," presented at the American Institute of Chemical Engineers Annual Meeting, Los Angeles, California, November 16-21, 1997.

A. A. Chialvo and P. T. Cummings, "The Importance of the Interplay Between Molecular Simulation and Neutron Scattering in Developing New Insights into the Structure of Water," presented at the American Institute of Chemical Engineers Annual Meeting, Los Angeles, California, November 16-21, 1997.

J. D. Moore, S. T. Cui, P. T. Cummings, and H. D. Cochran, "Lubricant Characterization by Molecular Simulation," presented at the American Institute of Chemical Engineers Annual Meeting, Los Angeles, California, November 16-21, 1997. 



\section{INTERNAL DISTRIBUTION}

1. J. M.Begovich

2. E. D. Collins

3. A. G. Croff

4. L. D. Duncan

5-60. B. J. Johnson

61. T. R. Jones

62-63. R. T. Jubin

64. J. A. Klein

65. L. E. McNeese

66. G. E. Michaels

67. B. D. Patton

68. D. E. Reichle

69. S. M. Robinson

70. M. K. Savage

71. T. W. Schmidt

72. G. W. Strandberg

73. R. M. Wham

74. ORNL Laboratory Records-RC

75. Central Research Library

76-77. ORNL Laboratory Records-OSTI 